\title{
Sliding Mode Control with PD Sliding Surface for High-Speed Railway Pantograph-Catenary Contact Force under Strong Stochastic Wind Field
}

\author{
Yang Song, ${ }^{1,2}$ Zhigang Liu, ${ }^{1,2}$ Huajiang Ouyang, ${ }^{3}$ Hongrui Wang, ${ }^{1,2}$ and Xiaobing Lu ${ }^{1,2}$ \\ ${ }^{1}$ State Key Laboratory of Traction Power, Southwest Jiaotong University, Chengdu, Sichuan 610031, China \\ ${ }^{2}$ School of Electrical Engineering, Southwest Jiaotong University, Chengdu, Sichuan 610031, China \\ ${ }^{3}$ School of Engineering, University of Liverpool, Brownlow Street, Liverpool L69 3GH, UK \\ Correspondence should be addressed to Zhigang Liu; liuzg@swjtu.cn
}

Received 24 August 2016; Revised 19 November 2016; Accepted 27 November 2016; Published 18 January 2017

Academic Editor: Sergio De Rosa

Copyright (C) 2017 Yang Song et al. This is an open access article distributed under the Creative Commons Attribution License, which permits unrestricted use, distribution, and reproduction in any medium, provided the original work is properly cited.

\begin{abstract}
As is well known, the external disturbance (especially the stochastic wind load) has nonnegligible effect on the operation of pantograph-catenary system, which may cause the strong fluctuation in contact force as well as the increased occurrence of contact loss. In order to improve the current collection quality of a high-speed railway pantograph-catenary system under a strong stochastic wind field, a sliding mode controller with a proportional-derivative (PD) sliding surface for a high-speed active pantograph is proposed. The nonlinear finite element procedure is employed to establish the catenary model. The fluctuating wind speeds along catenary are simulated using empirical spectrums. The buffeting forces exerted on contact and messenger wires are derived to construct the stochastic wind field along the catenary. A PD sliding surface is properly determined to guarantee that the mechanical impedance of pantograph head at the dominant frequencies of contact force decreases when the sliding surface approaches zero. Through several numerical simulations with different wind velocities and wind angles, the control performance of two popular control laws (proportional switching law and constant switching law) is evaluated.
\end{abstract}

\section{Introduction}

The recent decades have witnessed a rapid expansion of highspeed electrified railway in many countries around the world. The increase of the driving speed of high-speed trains leads to many new technical issues. One of them is the strong vibration of the pantograph-catenary system resulting in the deterioration of the current collection quality. Figure 1 describes the schematic of a pantograph-catenary system. The electric power is transmitted from the catenary to the locomotive via a pantograph installed on the roof. Obviously, the sliding contact between the pantograph collector and the contact wire is the most vulnerable point in this system, especially in high-speed driving conditions. Recently the contact quality between catenary and pantograph has been of great interest to many scholars, as it directly determines the current collection quality, restricting the driving speed limit of high-speed trains. An excessive contact force can aggravate the wear and fatigue of contact wire and pantograph collector. In contrast, an inadequate contact force may increase the possibility of the separation of the pantograph collector from the contact wire, which may lead to the occurrence of arcing and the interruption of electric power transmission. A stable contact force between the pantograph and catenary should be maintained to avoid the separation between the pantograph head and the contact wire, as well as to reduce the wear of pantograph strip and contact wire.

As is well known, mathematic modeling is an effective means to study the pantograph-catenary complex dynamic behaviour. In order to obtain the exact initial configuration of catenary, Lopez-Garcia et al. [1] proposed a nonlinear calculation procedure based on nonlinear cable equations. Tur et al. [2] proposed a shape-finding method for catenary system based on ANCF (absolute nodal coordinate formulation). In order to make sense of the dynamic behaviour of pantograph-catenary, the cosimulations of a finite element 


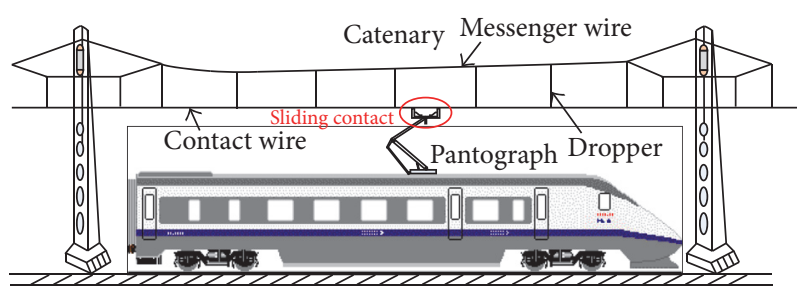

FIGURE 1: Schematic of the pantograph-catenary system.

procedure for catenary and multibody codes for pantograph were performed by Ambrósio et al. [3]. The damping of catenary was identified by Nåvik et al. [4] using the time series sampled on existing catenaries. An advanced detection method for contact wire irregularities was proposed by Wang et al. [5]. In order to exactly describe the geometrical nonlinearity of contact/messenger wire, a nonlinear finite element procedure was performed based on ANCF [6]. And the analytical formulations of nonlinear cable were utilized to describe the large deformation of contact/messenger wire by Song et al. [7]. On the other hand, in order to consider the complex operation conditions of pantograph-catenary system, Carnicero et al. [8] analysed the effect of locomotive vibration on pantograph-catenary interaction. Pombo et al. [9] analysed the influence of aerodynamics on pantographcatenary interaction. Song et al. [10] constructed the wind field along a catenary considering the stochastic wind from different directions and analysed the effect of stochastic wind load on pantograph-catenary interaction. The results of previous studies indicated that the effect of locomotive vibration on the contact force between catenary and pantograph was limited. In contrast, the effect of strong stochastic wind load was very significant.

Based on the study of pantograph-catenary dynamics, parameter optimization has been developed as a very general way to improve the dynamic performance of pantographcatenary systems. A design optimization procedure for a pantograph was conducted by Lee et al. [11], based on a sensitivity analysis of the pantograph-catenary system. Ambrósio et al. [12] studied the suspension characteristics of a pantograph head and proposed a corresponding optimization strategy to decrease the fluctuation in contact force. Rønnquist and Nåvik [13] used the frequency-analysis method to evaluate the upgrade of a catenary, and Nåvik et al. [14] suggested a new tension forces for a higher driving speed. Considering multiple-pantograph operation conditions, Liu et al. [15] studied the effect of interval between front and rear pantographs on dynamic performance.

However, a new design produced by the parameter optimization means the reconstruction of an existing pantograph-catenary system, which incurs a big cost and sometimes may not be easy to realize in reality. Besides parameter optimization of catenary-pantograph systems, control of pantographs is another effective way to maintain a stable contact force. Facchinetti et al. [16] performed a hardware-in-the-loop experiment for an active pantograph. In that work, an actuator was placed in parallel with the collector suspensions which could obtain better performance but is not convenient to be realized in an existing railway line. Generally, an actuator can be installed on the lower frame of the pantograph, which is more convenient to implement compared to [16] and does not lead to a large change to the original pantograph structure but poses a greater challenge to the control algorithm because it is far away from the contact interface.

Generally, the study of pantograph-catenary dynamic interaction belongs to moving-load dynamics problems [17]. Among them, vibration suppression of beams excited by moving loads has been of great interest to many scholars, as it has wide potentials in various engineering applications, such as bridge-vehicle interaction and vehicle-track interaction. $\mathrm{Pi}$ and Ouyang [18] used Lyapunov-based boundary control method for suppressing the vibration of a multispan beam subjected to moving masses. Stancioiu and Ouyang [19] proposed an effective time-varying optimal control strategy for a beam excited by a moving mass.

However, compared with the traditional moving-load control problems, whose objectives are to decrease the vibration response, the control objective of an active pantograph is to reduce the fluctuation in contact force and the contact loss between the pantograph collector and contact wire, simultaneously without reducing the contact force's mean value. Considering the particularity of the pantographcatenary system, only few states of the pantograph and the contact force can be detected, which can be used as feedback in a controller. Recently, various control algorithms for an active pantograph were proposed by many experts [20-28]. Normally, due to the strong nonlinear effect of the catenary on the pantograph, it is very difficult to design the controller based on the whole complex catenary-pantograph model directly. In the stage of the controller design, the catenary is always simplified as a one degree-of-freedom (DOF) model with time-varying stiffness (shown in Figure 2(a)) to facilitate development of the control strategy. Sometimes, a timevarying mass is also included (shown in Figure 2(b)). In Figure 2, $k_{\mathrm{c}}(t)$ and $m_{\mathrm{c}}(t)$ are the time-varying stiffness and mass of catenary. $m_{1}, k_{1}$, and $c_{1}$ are the mass, stiffness, and damping of the pantograph head, respectively; $m_{2}, k_{2}$, and $c_{2}$ are the mass, stiffness, and damping of the pantograph frame, respectively. $f_{c}$ is the pantograph-catenary contact force. $f_{0}$ is the static uplift force. $f_{u}$ is the control force.

Based on the simplified model shown in Figure 2(a), Lin et al. [20] developed a control strategy for an active pantograph by LQR (linear quadratic regulator). Recently, the robustness of an optimal control approach for an active pantograph was investigated considering the effect of actuator time delays [21]. Rachid [22] developed an LMI (Linear Matrix Inequality) control law to keep the contact force close to a desired value. O'Connor et al. [23] used the steady state matrix Riccati equation to design a controller for an active pantograph, which obtained over $50 \%$ reduction in the contact force variation. Pisano and Usai [24] proposed an output feedback control strategy based on higherorder sliding modes and high-gain observers, which had a good robustness and stability. Considering the locomotive vibration, Wang [25] developed a geometric framework to suppress the vibration of pantograph-catenary system. Based 


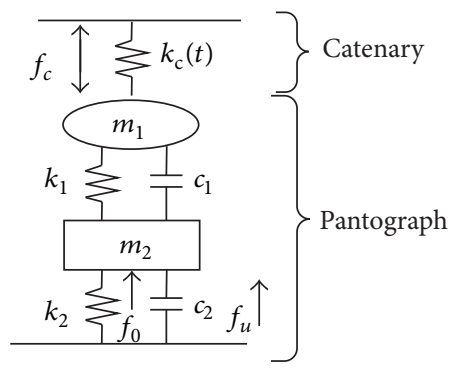

(a)

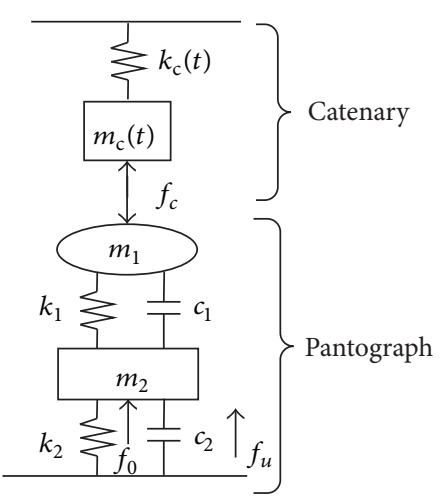

(b)

Figure 2: (a) Pantograph and simplified catenary model with time-varying stiffness. (b) Pantograph and simplified catenary model with time-varying stiffness and mass.

on the simplified model shown in Figure 2(b), Pisano and Usai [26] implemented a variable structure control (VSC) technique with sliding mode on a wire-actuated symmetric pantograph. Sanchez-Rebollo et al. [27] designed a PID controller for an active pantograph, which was the first attempt to implement a controller with a validated FEM catenary model.

It is obvious that the simplified models shown in Figure 2 can only reflect the unsmooth stiffness and mass distribution of the catenary without considering some other nonlinear disturbances from catenary to pantograph in the stage of controller design. On the other hand, except the work done by Sanchez-Rebollo et al. [27] and Pappalardo et al. [28], none of the other works implemented their controllers with a more realistic nonlinear validated catenary model. However, the validation of the controller with a realistic nonlinear catenary model is very important in the theoretical study of the pantograph control before it can be evaluated through a field experiment in a real railway line. Furthermore, to the best of the authors' knowledge, the complex environmental perturbations (especially the stochastic wind along catenary) have not been considered when the control strategy was implemented. Due to these perturbations, the fluctuation in contact force increases significantly, and the separation between the pantograph head and contact wire occurs more frequently. The efficiency of the control strategy should be evaluated under these realistic complex operation conditions, which definitely exist in a real railway line. The robustness of the controller also needs a further investigation with strong external perturbations.

This paper addresses these difficulties of pantograph control and proposes a sliding mode control (SMC) strategy with a PD sliding surface for a high-speed pantograph. Compared with other control strategies, SMC seems to be convenient to realize the control objective of keeping the contact force close to a desired value through defining a proper sliding surface. SMC was shown to be very suitable for nonlinear time-varying systems. For example, Pi and Ouyang [29] also found that SMC had a good performance in suppressing the vibration of a beam excited by a moving mass.
In [26], SMC was firstly introduced in the active pantograph control and a very simple control law was proposed. But the oversimplified model used in that work cannot guarantee its validity in a more realistic pantograph-catenary model.

To address the shortcomings of the previous studies, instead of the oversimplified model in Figure 2, a nonlinear FEM catenary model under the stochastic wind field along the catenary is established. The contact force between the pantograph and catenary is chosen as the feedback signal. The transfer function between the pantograph velocity and contact force (called mechanical impedance) is introduced as an auxiliary indicator to determine the sliding surface parameters. Then several numerical simulations with two popular control laws (proportional switching law and constant switching law) are implemented to evaluate the control performance under a strong stochastic wind field. In order to verify the advantage of the proposed control strategy, the control performance is compared with EN 50318 reference model reported in the literature. This work is a theoretical attempt to introduce the PD sliding mode control strategy into pantograph-catenary dynamics under more complex and realistic operation conditions than previous studies, to improve the current collection quality of high-speed railway pantograph-catenary system.

\section{Establishment of Pantograph-Catenary System with Stochastic Wind Load}

Based on the authors' previous work $[7,10]$, the pantographcatenary dynamic model with stochastic wind load as shown in Figure 3 is established in this section.

2.1. Modeling of Catenary-Pantograph. Normally, a catenary system is comprised of three main components: the contact wire, the messenger wire, and droppers, as shown in Figure 3. In order to properly describe the nonlinear behaviour under strong wind field, the contact/messenger wire is discretized as a number of nonlinear cable elements based on the FEM, and the dropper is modeled by the nonlinear string element which behaves like one-side spring. Then a nonlinear finite 


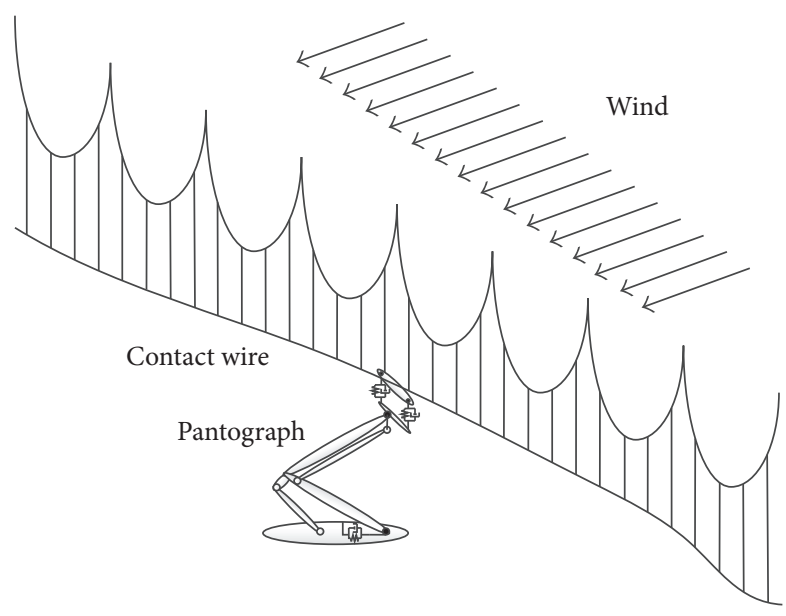

Figure 3: Pantograph-catenary system with wind load.

element dynamic procedure is performed to solve the initial configuration and the dynamic response of catenary. The global stiffness matrix $\mathbf{K}_{C}(t)$ of catenary can be formulated through the FEM at any time instant $t$. The global lumpedmass matrix $\mathbf{M}_{C}$ and the global damping matrix $\mathbf{C}_{C}$ can also be obtained. The equation of motion for catenary can be written as

$$
\mathbf{M}_{C} \Delta \ddot{\mathbf{X}}_{C}(t)+\mathbf{C}_{C} \Delta \dot{\mathbf{X}}_{C}(t)+\mathbf{K}_{C}(t) \Delta \mathbf{X}_{C}(t)=\Delta \mathbf{F}_{C}(x, t)
$$

in which $\Delta \ddot{\mathbf{X}}_{C}(t), \Delta \dot{\mathbf{X}}_{C}(t)$, and $\Delta \mathbf{X}_{C}(t)$ are the incremental vectors of the global acceleration, velocities, and displacements of catenary. $\Delta \mathbf{F}_{C}(x, t)$ on the right side is the incremental vector of the excitation.

A two-DOFs pantograph model (as shown in Figure 2) is adopted. The contact between the pantograph head and the contact wire is realized by a penalty method, in which an assumption of "contact stiffness" is defined. The contact force can be calculated based on a penalisation of the interpenetration between the pantograph strip and the contact wire. The contact force can be calculated by

$$
f_{c}= \begin{cases}K_{S}\left(y_{1}-y_{c}\right) & y_{1} \geq y_{c} \\ 0 & y_{1}<y_{c}\end{cases}
$$

in which $K_{S}$ is the contact stiffness. $y_{1}$ is the vertical displacement of the pantograph head. $y_{c}$ is the vertical displacement of the contact wire in the contact point. The static uplift force is determined by a formula in a SIEMNS simulation report mentioned in [7].

2.2. Validation of Pantograph-Catenary Model. Several numerical simulations have been conducted in [7] to verify the accuracy of the static configuration of catenary and the validation of the dynamic solution. Here, the newest benchmark proposed by Bruni et al. [30] is adopted to conduct a further validation of the presented model. Table 1 shows the dynamic simulation results compared to the reference values in the benchmark. It is observed that two sets of the results are only slightly different.
TABLE 1: Validation of the present model according to the benchmark results.

\begin{tabular}{lccc}
\hline Indicators & Benchmark & Simulation & Error (\%) \\
\hline Speed (km/s) & 320 & 320 & 0 \\
Mean contact force (N) & 169 & 171.25 & 1.3 \\
Standard deviation (N) & 53.91 & 55.21 & 2.4 \\
Max. real value (N) & 313.22 & 321.79 & 2.7 \\
Min. real value (N) & 60.40 & 56.84 & -5.9 \\
Banded SD 0-2 Hz (N) & 38.27 & 39.11 & 2.2 \\
Banded SD 0-5 Hz (N) & 41.04 & 40.52 & -1.3 \\
Banded SD 5-20 Hz (N) & 34.80 & 36.07 & 3.6 \\
PPA of the vertical & 47.58 & 45.31 & 4.8 \\
displacement (mm) & & 60.17 & 1.8 \\
Max. uplift at support (mm) & 59.12 & &
\end{tabular}

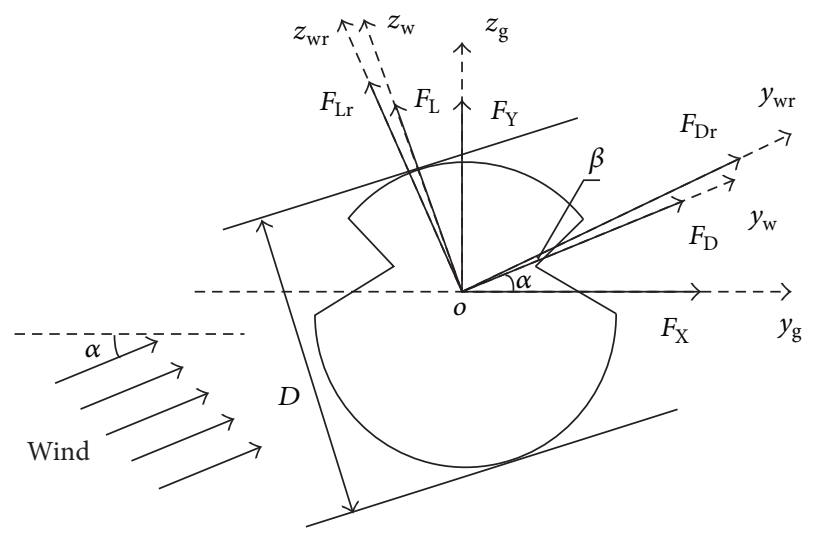

FIGURE 4: Sketch of contact wire section against wind load.

2.3. Stochastic Wind Field. Figure 4 shows the contact wire cross section under wind load. $U$ and $\alpha$ are the wind speed and angle of attack. $L$ is the length of contact wire. $D$ is the diameter of the cross section of contact wire. According to the derivation in [10], the buffeting forces acting on contact wire can be written as

$$
\begin{aligned}
F_{\mathrm{D}} & =\frac{1}{2} \rho_{\text {air }} U^{2} L D\left[C_{\mathrm{D}}\left(\alpha_{0}\right) \cdot \frac{2 u(t)}{U}\right. \\
& \left.+\left[\dot{C_{\mathrm{D}}}\left(\alpha_{0}\right)-C_{\mathrm{L}}\left(\alpha_{0}\right)\right] \cdot \frac{w(t)}{U}\right]+\frac{1}{2} \\
& \cdot \rho_{\text {air }} U^{2} D L C_{\mathrm{D}}\left(\alpha_{0}\right) \\
F_{\mathrm{L}} & =\frac{1}{2} \rho_{\text {air }} U^{2} L D\left[C_{\mathrm{L}}\left(\alpha_{0}\right) \cdot \frac{2 u(t)}{U}\right. \\
& \left.+\left[\dot{C}_{\mathrm{L}}\left(\alpha_{0}\right)+C_{\mathrm{D}}\left(\alpha_{0}\right)\right] \cdot \frac{w(t)}{U}\right]+\frac{1}{2} \\
& \cdot \rho_{\text {air }} U^{2} D L C_{\mathrm{L}}\left(\alpha_{0}\right)
\end{aligned}
$$

in which $\rho_{\text {air }}$ is the density of air. $\alpha_{0}$ is the initial angle of attack. $C_{\mathrm{D}}\left(\alpha_{0}\right)$ and $C_{\mathrm{L}}\left(\alpha_{0}\right)$ are the drag and lift coefficients at the angle of attack $\alpha_{0}$, which can be calculated through CFD 


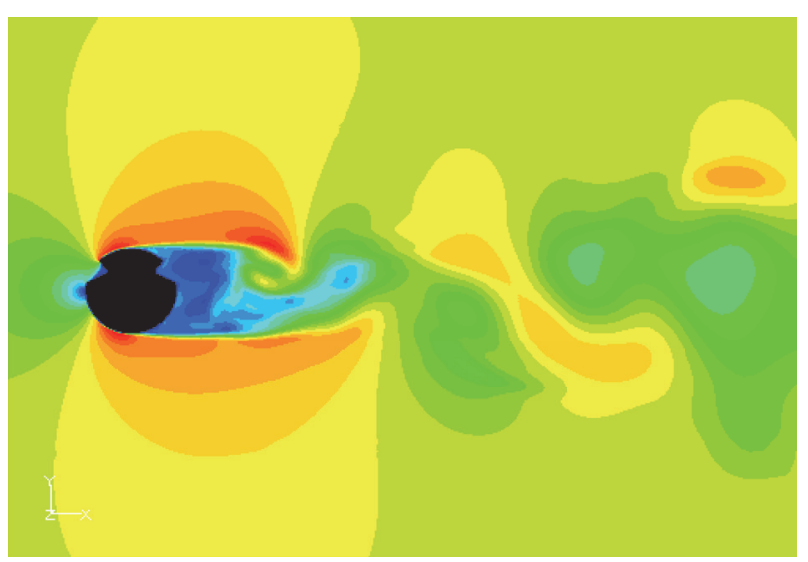

FIGURE 5: Nephogram of the flow velocity around the contact wire cross section in CFD calculation.

or measured in a wind tunnel experiment. $w(t)$ and $u(t)$ are the time-histories of the vertical and horizontal wind velocity.

By transforming (3a) and (3b) to the finite element coordinate, the formulation of the aerodynamic forces that can be used in the FEM model directly is obtained as follows:

$$
\begin{aligned}
& F_{\mathrm{X}}=F_{\mathrm{D}} \cos \left(\alpha_{0}\right)-F_{\mathrm{L}} \sin \left(\alpha_{0}\right) \\
& F_{\mathrm{Y}}=F_{\mathrm{D}} \sin \left(\alpha_{0}\right)+F_{\mathrm{L}} \cos \left(\alpha_{0}\right) .
\end{aligned}
$$

In order to obtain the wind load acting on the catenary, the aerodynamic coefficients $C_{\mathrm{D}}(\alpha)$ and $C_{\mathrm{L}}(\alpha)$ and the fluctuating wind velocity $u(t)$ and $w(t)$ should be determined.

The CFD software-ANSYS Fluent-is utilized to determine the aerodynamic coefficients $C_{\mathrm{D}}(\alpha)$ and $C_{\mathrm{L}}(\alpha)$. In this paper, the CuAg0.1AC120-type contact wire is chosen as the object of analysis. Simulation conditions (including the boundary conditions and mesh properties) are defined according to [10]. Figure 5 shows the nephogram of the flow velocity around the contact wire cross section in the CFD calculation. The calculation results of the aerodynamic coefficients are shown in Figure 6 [10].

The empirical formulations of the wind velocity spectrum are utilized to simulate the fluctuating wind velocities in different directions. The nondimensional form of the Davenport spectrum for horizontal wind speed $S_{z}$ is [31]

$$
\frac{n S_{z}(n)}{V_{1}^{2}}=4 \kappa \frac{x^{2}}{\left(1+x^{2}\right)^{4 / 3}}
$$

in which $x=4000 n / V_{1}^{2}, \kappa$ is the surface drag coefficient, $n$ is the frequency of fluctuating wind, and $V_{1}$ is the velocity at reference height $(10 \mathrm{~m})$. The Panofsky spectrum for vertical wind speed $S_{w}$ is [32]

$$
\frac{n S_{w}(n, z)}{V_{z 1}^{2}}=1.1 \frac{f}{(1+4 f)^{2} \log _{e}^{2}\left(z_{1} / z_{0}\right)},
$$

where $f=n z / V_{1}, V_{z 1}$ is the reference velocity at height $z_{1}$, and $z_{0}$ is the roughness length.
The variance of the spatial distribution of the stochastic wind velocity is considered by defining the spatial correlation function using Wiener-Khinchin equation. Through fourthorder AR model, the time-histories of the vertical and horizontal wind velocities can be generated, in which the stochastic feature of the fluctuating wind velocity in time-domain is properly considered. In this paper, an existing high-speed pantograph-catenary system constructed in China is studied [7]. Consider that the longitudinal interval in simulation for the fluctuating wind is $10 \mathrm{~m}$. The simulation results of the fluctuating wind velocities and their spectrums at the first point of this longitudinal interval are shown in Figure 7 (in which the steady wind speed is chosen as $20 \mathrm{~m} / \mathrm{s}$ ). It is found that the autopower spectrum shows excellent agreement with the target spectrum. The effect of the stochastic wind is a low-frequency disturbance, whose dominant frequency is normally less than $1 \mathrm{~Hz}$.

\section{Definition of the Sliding Surface}

According to the literature [16], the contact force between the pantograph collector and the contact wire can be measured through a contact force sensor, which directly reflects the contact quality of the pantograph-catenary system. So the contract force can be utilized as the feedback signal in the controller. In order to realize the control objective, a PD sliding surface is defined as follows:

$$
S(t)=q_{\mathrm{p}} e(t)+q_{\mathrm{d}} \dot{e}(t)
$$

in which $e(t)=f_{r}-f_{c}(t) . f_{r}$ is the desired value of contact force (which is normally the mean value of contact force). The control force $f_{u}(t)$ is determined by the sliding surface $S(t)$ to keep the sliding surface $S(t)$ close to 0 . So the values of the parameters $q_{\mathrm{p}}$ and $q_{\mathrm{d}}$ are of great importance. Normally, the parameters of a sliding surface can be determined by experience or the placement of poles to guarantee the stability of the system. However, there seem to be no previous studies or experience on how to determine the sliding surface. In this paper, the mechanical impedance of pantograph head is introduced as an auxiliary indicator to define the sliding surface parameters.

When the control force is exerted on the lower frame of pantograph, the equation of motion for the pantograph can be written as

$$
\begin{aligned}
& m_{1} \frac{\mathrm{d}^{2} y_{1}(t)}{\mathrm{d} t^{2}}+c_{1}\left(\frac{\mathrm{d} y_{1}(t)}{\mathrm{d} t}-\frac{\mathrm{d} y_{2}(t)}{\mathrm{d} t}\right) \\
& \quad+k_{1}\left(y_{1}(t)-y_{2}(t)\right)=-f_{c}(t) \\
& m_{2} \frac{\mathrm{d}^{2} y_{2}(t)}{\mathrm{d} t^{2}}+c_{2}\left(\frac{\mathrm{d} y_{2}(t)}{\mathrm{d} t}-\frac{\mathrm{d} y_{1}(t)}{\mathrm{d} t}\right)+c_{1} \frac{\mathrm{d} y_{2}(t)}{\mathrm{d} t} \\
& \quad+k_{2}\left(y_{2}(t)-y_{1}(t)\right)+k_{1} y_{2}(t)=f_{0}+f_{u}(t) .
\end{aligned}
$$

Normally, the static uplift force $f_{0}$ is very close to the mean value of contact force $f_{r}$. So, it can be assumed that $f_{0}=f_{r}$. The contact force can be expressed as

$$
f_{c}(t)=f_{0}+\Delta f_{c}(t)
$$




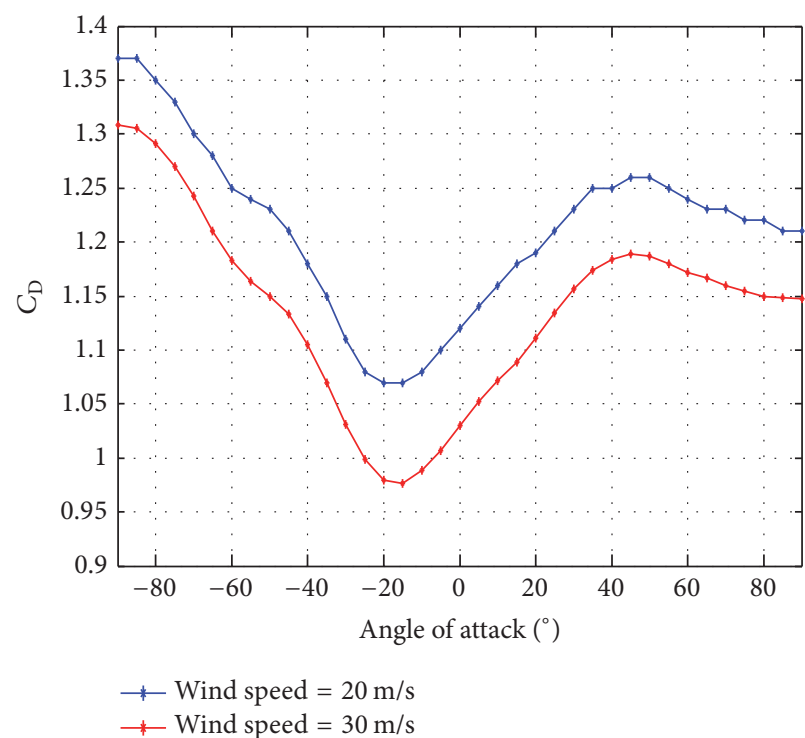

(a) $C_{\mathrm{D}}$

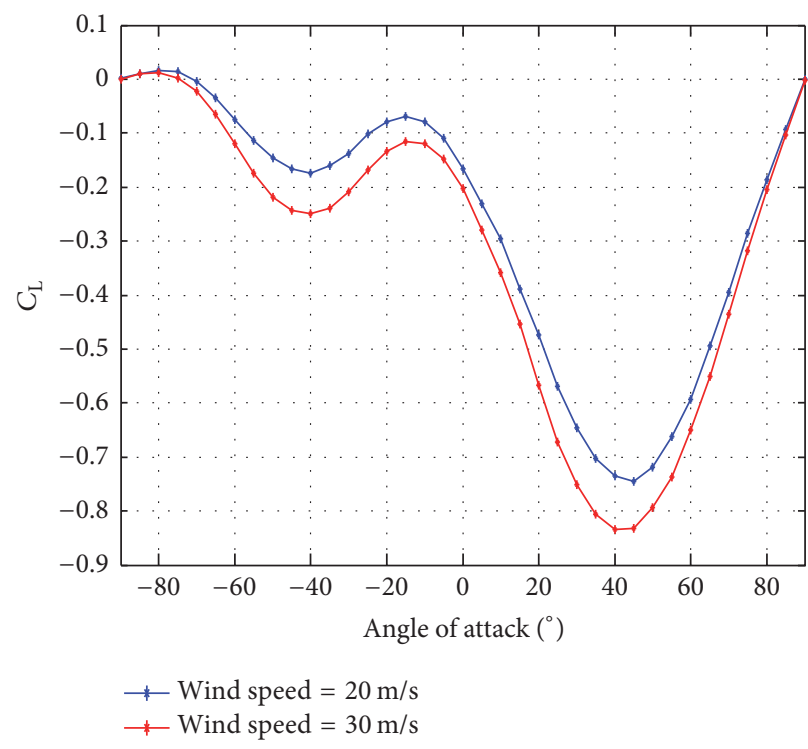

(b) $C_{\mathrm{L}}$

FIGURE 6: Simulation results of aerodynamic coefficients of contact wire cross section.
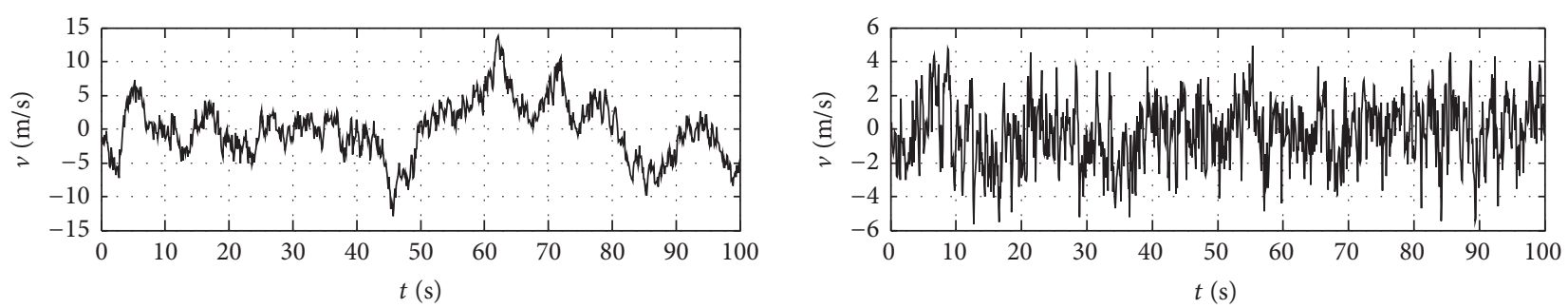

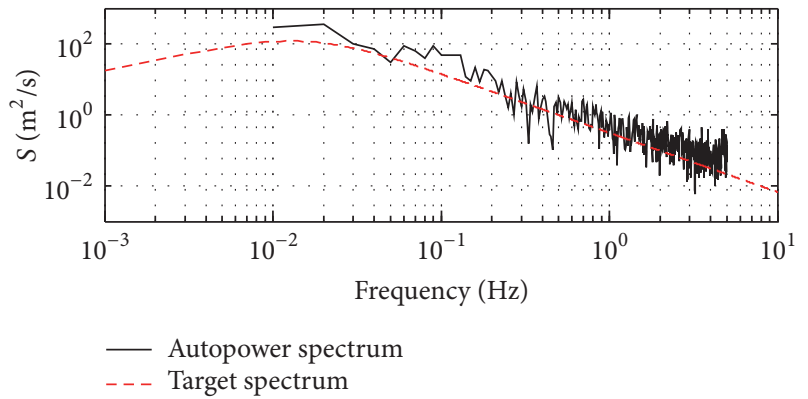

(a) Horizontal wind velocity

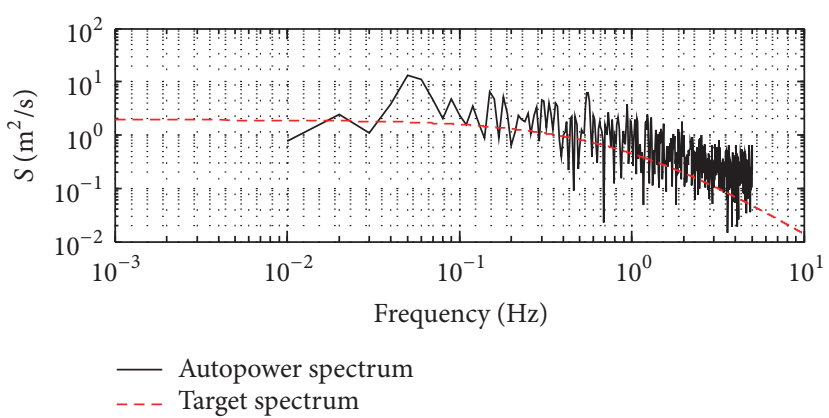

(b) Vertical wind velocity

FIGURE 7: Simulation results of fluctuating wind velocity and their power spectrums.

in which $\Delta f_{c}(t)$ is the fluctuation in contact force around its mean value $f_{0}$. The mechanical impedance $H(s)$, a transfer function between the fluctuation of contact force $\Delta F_{c}(s)$ and the velocity of pantograph head $V_{1}(s)$, is established by taking Laplace transformation of (8) and ignoring the constant terms as

$$
H(s)=\frac{\Delta F_{c}(s)}{V_{1}(s)}=\frac{m_{1} m_{2} s^{4}+\left(c_{2} m_{1}+c_{1} m_{1}+c_{1} m_{2}\right) s^{3}+\left(k_{1} m_{1}+k_{2} m_{1}+k_{1} m_{2}+c_{1} c_{2}\right) s^{2}+\left(c_{1} k_{2}+c_{2} k_{1}\right) s+k_{1} k_{2}}{\left(m_{2} s^{2}+\left(c_{1}+c_{2}\right) s+k_{1}+k_{2}-\left(k_{1}+c_{1} s\right)\left(q_{d} s+q_{p}\right)\right) s}
$$

in which $s$ is the Laplace constant. As the control force $f_{u}(t)$ is determined by the sliding surface $S(t)$, let $S(t)$ replace $f_{u}(t)$ in
(10), to analyse the influence of the sliding surface parameters on the mechanical impedance of pantograph head in the 


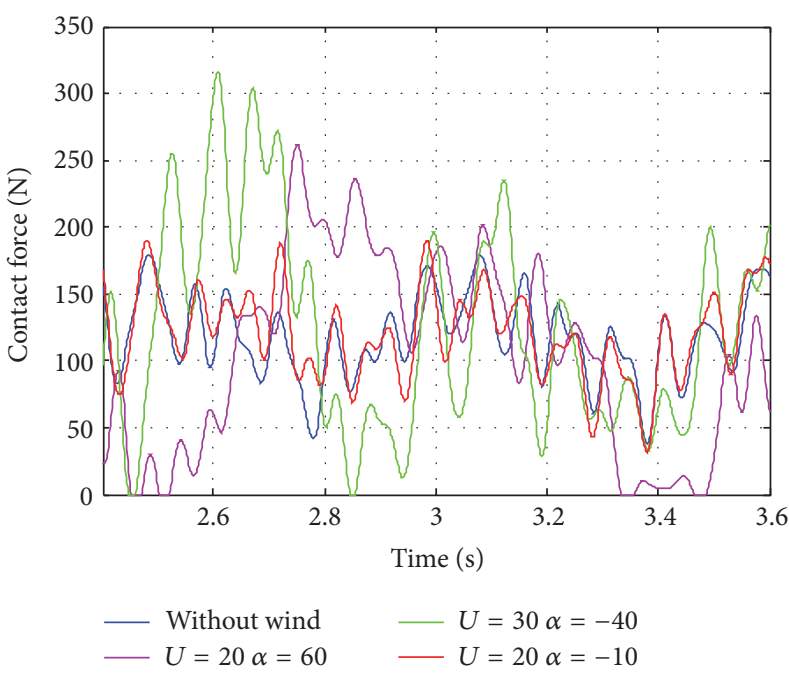

(a) Contact force

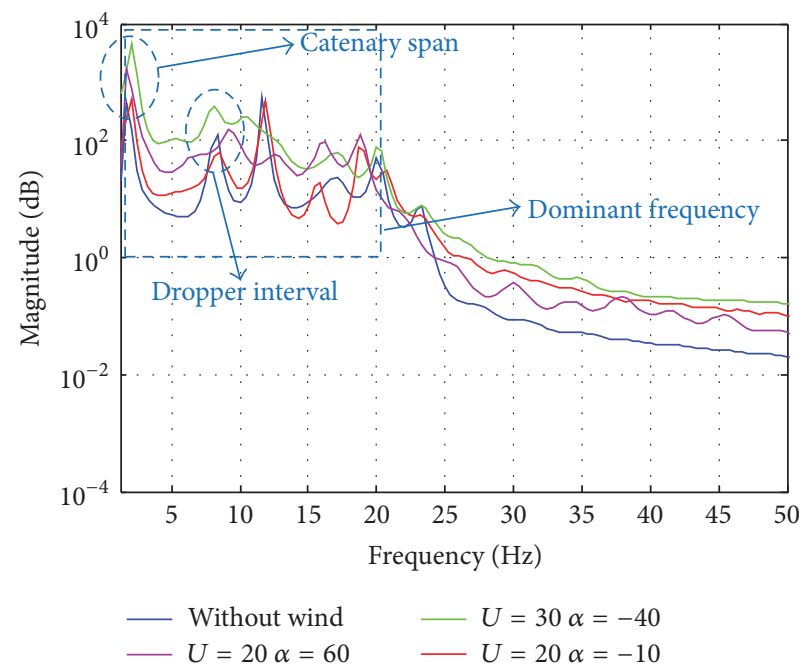

(b) Spectral density of contact force

FIgURE 8: Contact force and its spectral density.

stage of the controller design. In [33], transfer function $H(s)$ is defined as the mechanical impedance of the pantograph, which can be assumed as an important reflection of the dynamic performance of the pantograph under the excitation of fluctuating wind. A lower mechanical impedance of the pantograph head at the dominant frequencies of contact force can guarantee a good current collection quality of the pantograph-catenary system. In contrast, a large mechanical impedance of the pantograph head may lead to an increase of the fluctuation in contact force. So, in this section, according to (10), the contribution of each of the parameters $q_{\mathrm{p}}$ and $q_{\mathrm{d}}$ to the mechanical impedance is analysed for the definition of the sliding surface.

Before the analysis of the mechanical impedance of pantograph head, the range of the dominant frequency of contact force should be determined through the frequency analysis of the contact force. Using the pantograph-catenary model established in Section 2, the simulation results of contact force are shown in Figure 8(a), in which, the driving speed is $300 \mathrm{~km} / \mathrm{h}$, and three sets of wind field parameters are adopted (which are $U=20 \mathrm{~m} / \mathrm{s}$ with $\alpha=60^{\circ}, U=20 \mathrm{~m} / \mathrm{s}$ with $\alpha=-10^{\circ}$, and $U=30 \mathrm{~m} / \mathrm{s}$ with $\alpha=-30^{\circ}$ ). The results of corresponding spectral density are shown in Figure 8(b). From the spectral density of contact force, the frequency components related to the catenary span and dropper interval can be clearly observed. The dominant frequency of contact force resides mainly in the range from $1.67 \mathrm{~Hz}$ (which is related to the catenary span $(50 \mathrm{~m})$ traversed by a pantograph with the driving speed of $300 \mathrm{~km} / \mathrm{h}$ ) to $20 \mathrm{~Hz}$. The effect of the environmental wind leads to an increase of the input energy into the pantograph-catenary system at most frequencies but does not result in a significant change of the range of dominant frequency.

By substituting $s=j 2 \pi f$ to (10), the effect of $q_{\mathrm{p}}$ and $q_{\mathrm{d}}$ on the mechanical impedance at the dominant frequencies of contact force is analysed. The effect of parameter $q_{\mathrm{p}}$ is investigated firstly. The Bode diagram of the transfer function
$H(s)$ at different $q_{\mathrm{p}}$ is plotted in Figure 9(a). It is clearly found that positive $q_{\mathrm{p}}$ has a significant contribution to decreasing the mechanical impedance at the dominant frequencies of contact force (especially from $1.5 \mathrm{~Hz}$ to $20 \mathrm{~Hz}$ ).

Similar to the analysis of the effect of $q_{\mathrm{p}}$, the mechanical impedance with different $q_{\mathrm{d}}$ is plotted in Figure 9(b). It is clearly found that a positive $q_{\mathrm{d}}$ can lead to a total increase of the mechanical impedance at all frequencies, which may result in a deterioration of the current collection quality. Sanchez-Rebollo et al. [27] have also drawn a similar conclusion in their work: a positive value of the differential parameter gain in their PID controller can cause the instability of the system and the increase of fluctuation in contact force. In contrast, it can also be observed that a negative $q_{\mathrm{d}}$ can lead to the decrease of the mechanical impedance at all frequencies. In order to observe the effect of $q_{\mathrm{p}}$ and $q_{\mathrm{d}}$ on the mechanical impedance more clearly, the surface of the mechanical impedance at the most significant frequency $1.67 \mathrm{~Hz}$ (which is corresponding to the catenary span), versus $q_{\mathrm{p}}$ and $q_{\mathrm{d}}$ in the revised manuscript, is shown in Figure 10. Similar conclusion to the above analysis can be drawn. So, through the analysis of the effect of each of the parameters on the mechanical impedance of pantograph head, it is concluded that the sliding surface should be comprised of a positive $q_{\mathrm{p}}$ and a negative $q_{\mathrm{d}}$.

\section{Numerical Simulations}

As mentioned in the Introduction, there are two control laws to determine the control force through the sliding surface $S(t)$. One is the constant switching law and the other is the proportional switching law.

For the constant switching law, the control force switches between a lower and an upper bound, which can be described as

$$
f_{u}(t)= \begin{cases}u & S(t)>0 \\ -u & S(t)<0\end{cases}
$$




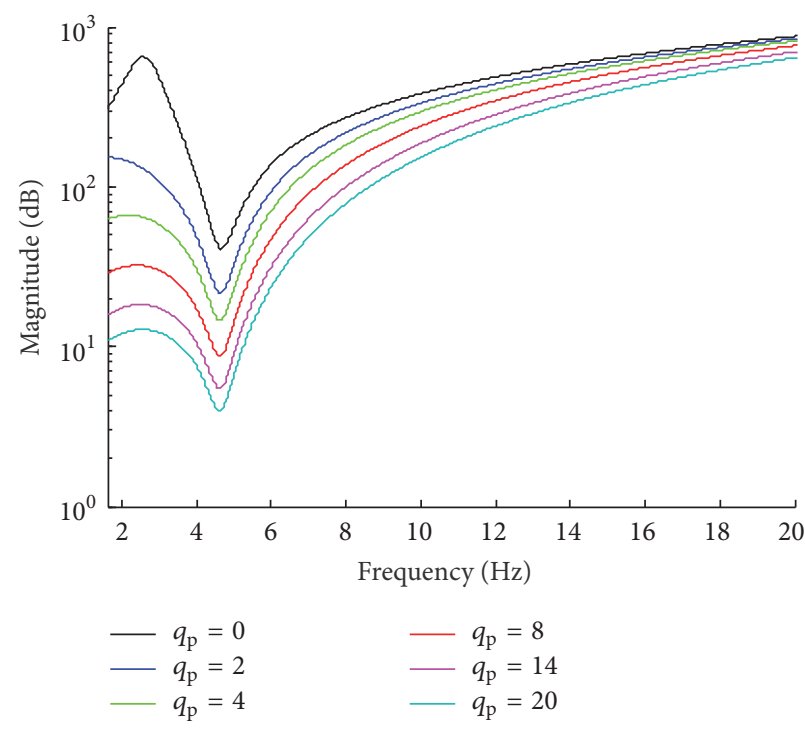

(a) Mechanical impedance with different $q_{\mathrm{p}}$

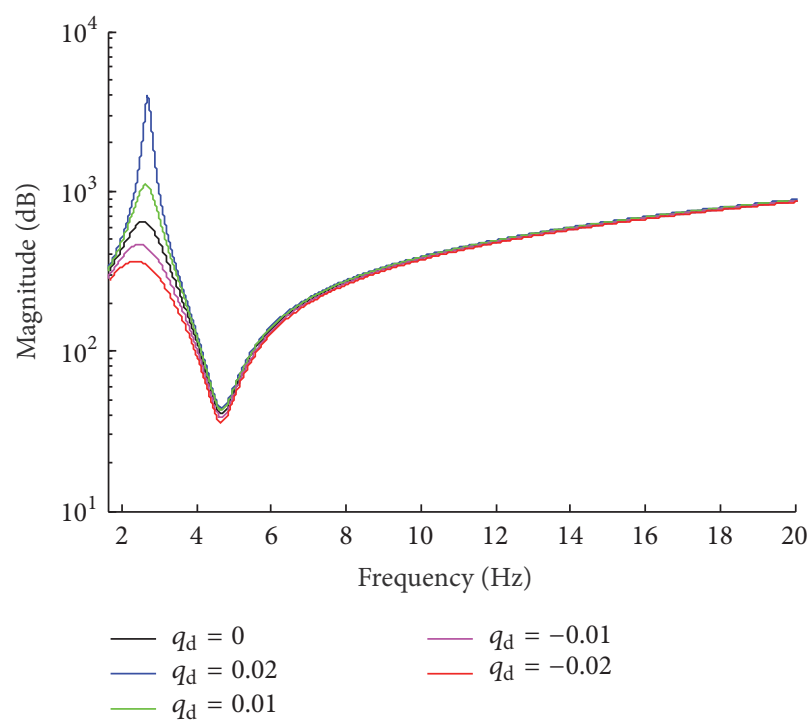

(b) Mechanical impedance with different $q_{\mathrm{d}}$

FIGURE 9: Mechanical impedance of pantograph head with $q_{\mathrm{p}}$ and $q_{\mathrm{d}}$.

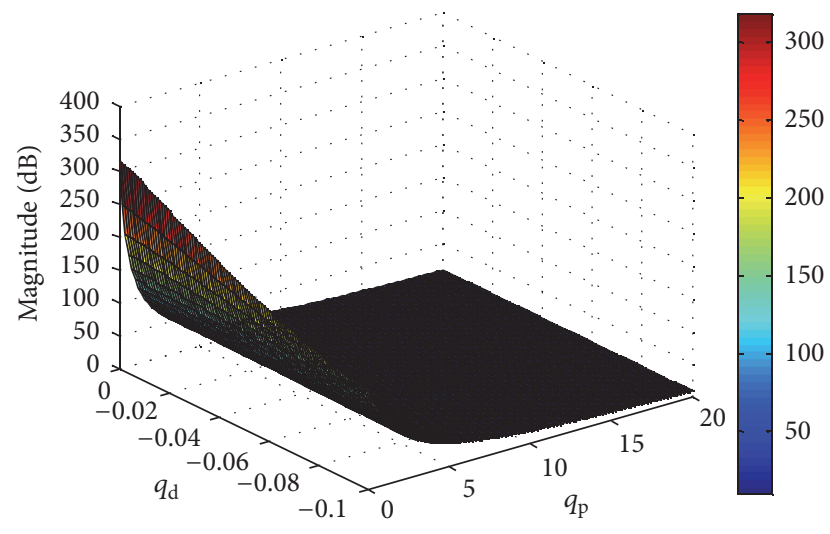

FIGURE 10: Surface of mechanical impedance at $1.67 \mathrm{~Hz}$ versus $q_{\mathrm{p}}$ and $q_{\mathrm{d}}$.

in which $f_{u}(t)$ is the control force. $u$ is the bound of control force.

For the proportional switching law, the control force is determined by a smooth proportional function and the sliding surface as

$$
f_{u}(t)=|\alpha e(t)+\beta \dot{e}(t)| \operatorname{sgn}(S(t)),
$$

where $\alpha$ and $\beta$ are the control gains in the proportional switching law. Compared with the constant switching law, the control force changes more smoothly against time.

In order to determine the values of $q_{\mathrm{p}}$ and $q_{\mathrm{d}}$ in the sliding surface, a lot of simulations are conducted to show how the sliding surface affects the control performance. Figure 11 shows the calculation results of standard deviation of contact force versus $q_{\mathrm{p}}$ and $q_{\mathrm{d}}$. In this discussion, the control law is selected as a proportional switching law with $\alpha=0.4$ and $\beta=-2 \times 10^{-4}$. From Figure 11, it can be seen that when

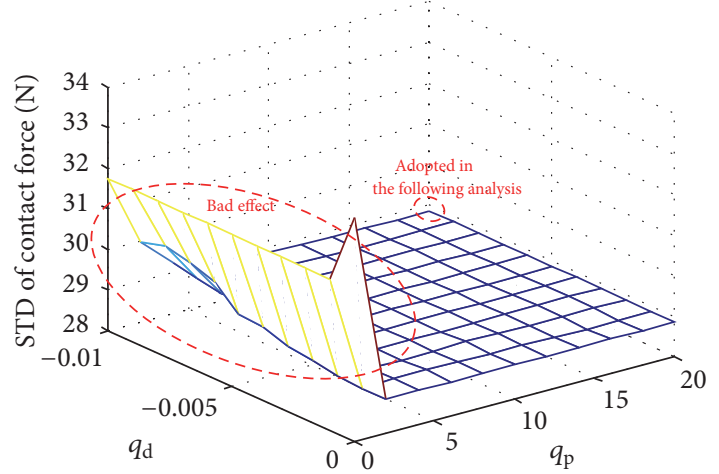

FIGURE 11: Standard deviation of contact force versus $q_{\mathrm{p}}$ and $q_{\mathrm{d}}$.

$q_{p}$ increases more than 0 , the standard deviation generally cannot be largely influenced by the change of $q_{\mathrm{p}}$ and $q_{\mathrm{d}}$. In the following analysis, through comparing the values of $e(t)$ and its derivative $\dot{e}(t)$, the parameters of sliding surface are defined as $q_{\mathrm{p}}=20$ and $q_{\mathrm{d}}=-0.01$ for the DSA-380 pantograph, which shows a relatively good performance in this analysis.

4.1. Comparison of Two Control Laws without Wind Load. In this section, several numerical simulations are conducted to evaluate the control performance using the two control laws. For the constant switching law, the control force bound is chosen as $10 \mathrm{~N}, 20 \mathrm{~N}, 30 \mathrm{~N}, 40 \mathrm{~N}, 50 \mathrm{~N}, 60 \mathrm{~N}$, and $70 \mathrm{~N}$, separately. For the proportional switching law, three sets of control gains are defined as follows:

$$
\begin{aligned}
& \text { Case 1: } \alpha=0.2 \text { and } \beta=-1 \times 10^{-4} \\
& \text { Case 2: } \alpha=0.4 \text { and } \beta=-2 \times 10^{-4} \\
& \text { Case 3: } \alpha=0.8 \text { and } \beta=-4 \times 10^{-4}
\end{aligned}
$$


TABLE 2: The results of standard deviation and maximum control force.

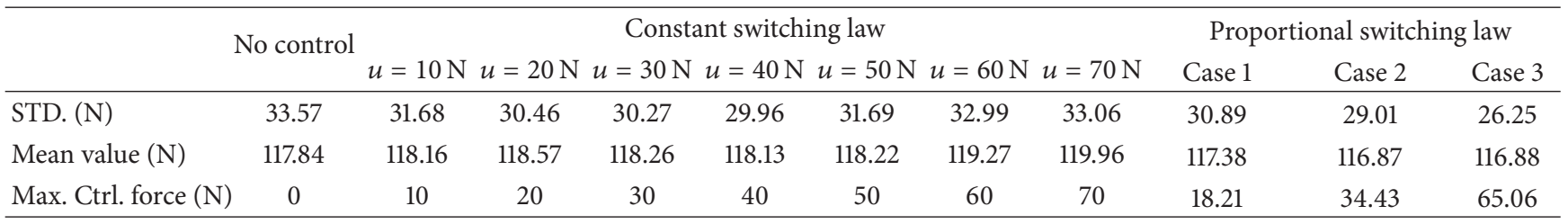

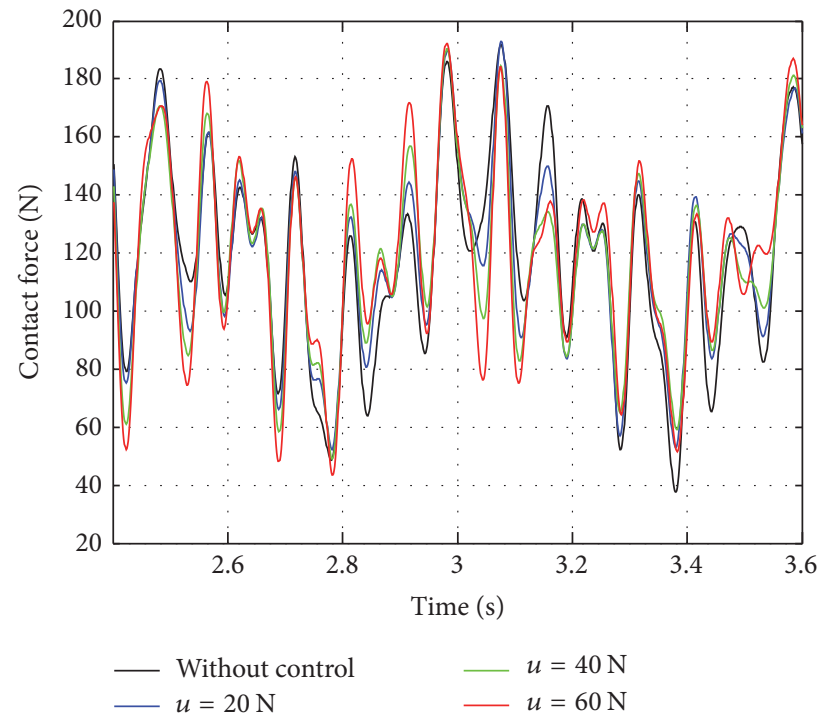

FIGURE 12: Contact force with constant switching law.

The results of contact force with constant switching law are shown in Figure 12. It should be noted that the results are filtered with the frequency range of $0-20 \mathrm{~Hz}$, according to the requirement of EN 50318. The results of contact force with the proportional switching law are shown in Figure 13(a). The corresponding control force is shown in Figure 13(b). From the results of contact force, it is not very clear to see how the controller contributes to decrease of the fluctuation in contact force. The results of standard deviation of contact force, mean value of contact force, and the corresponding maximum control force using different control strategies are shown in Table 2 . It can be clearly found that, due to the effect of the controller, the standard deviation of contact force experiences a decrease. For the constant switching law, the best result appears at $u=40 \mathrm{~N}$. When $u$ increases from $10 \mathrm{~N}$ to $40 \mathrm{~N}$, the control effect increases accordingly. However, when $u$ exceeds $40 \mathrm{~N}$, the control performance begins to become worse. For the proportional switching law, it can be found that, from case 1 to case 3 , the standard deviation experiences a significant decrease, which means an improvement of the control performance. Through the comparison between the two control laws, it is found that the proportional switching law has a better potential in decreasing the contact force fluctuation. The proportional switching law of case 3 can make the standard deviation decrease to 26.25 using the maximum control force of $65.06 \mathrm{~N}$. Through the analysis of the mean value of contact force, it is found that the controller cannot lead to a large change of the mean value of contact force.

From Figure 13, it can also be found that a large control force can only result in a small change of the contact force; for instance, at $t=2.78 \mathrm{~s}$, the control forces are approximately $17 \mathrm{~N}, 31 \mathrm{~N}$, and $58 \mathrm{~N}$ with each of the cases, which however lead to very small difference in the contact force $(\leq 10 \mathrm{~N})$. This phenomenon can be explained by the frequency response between the control force and the contact force.

As is well known, the equation of motion for the pantograph can be written as

$$
\begin{aligned}
& m_{1} \frac{\mathrm{d}^{2} y_{1}(t)}{\mathrm{d} t^{2}}+c_{1}\left(\frac{\mathrm{d} y_{1}(t)}{\mathrm{d} t}-\frac{\mathrm{d} y_{2}(t)}{\mathrm{d} t}\right) \\
& \quad+k_{1}\left(y_{1}(t)-y_{2}(t)\right)=-f_{c}(t) \\
& m_{2} \frac{\mathrm{d}^{2} y_{2}(t)}{\mathrm{d} t^{2}}+c_{2}\left(\frac{\mathrm{d} y_{2}(t)}{\mathrm{d} t}-\frac{\mathrm{d} y_{1}(t)}{\mathrm{d} t}\right)+c_{1} \frac{\mathrm{d} y_{2}(t)}{\mathrm{d} t} \\
& \quad+k_{2}\left(y_{2}(t)-y_{1}(t)\right)+k_{1} y_{2}(t)=f_{0}+f_{u}(t) .
\end{aligned}
$$

In this discussion, the effect of catenary on pantograph is simplified to simple time-varying stiffness $K_{s}(t)$ exerted on the pantograph head. So the contact force can be expressed by

$$
f_{c}(t)=K_{s}(t) y_{1}(t) .
$$

The equivalent stiffness $K_{s}(t)$ along the catenary can be calculated through applying a force moving along the contact wire, which has been done in our previous work [7].

Substituting (14) to (13), the simplified equation of motion for pantograph-catenary can be written as

$$
\begin{aligned}
& m_{1} \frac{\mathrm{d}^{2} y_{1}(t)}{\mathrm{d} t^{2}}+c_{1}\left(\frac{\mathrm{d} y_{1}(t)}{\mathrm{d} t}-\frac{\mathrm{d} y_{2}(t)}{\mathrm{d} t}\right) \\
& \quad+k_{1}\left(y_{1}(t)-y_{2}(t)\right)=-K_{s}(t) y_{1}(t) \\
& m_{2} \frac{\mathrm{d}^{2} y_{2}(t)}{\mathrm{d} t^{2}}+c_{2}\left(\frac{\mathrm{d} y_{2}(t)}{\mathrm{d} t}-\frac{\mathrm{d} y_{1}(t)}{\mathrm{d} t}\right)+c_{1} \frac{\mathrm{d} y_{2}(t)}{\mathrm{d} t} \\
& \quad+k_{2}\left(y_{2}(t)-y_{1}(t)\right)+k_{1} y_{2}(t)=f_{0}+f_{u}(t)
\end{aligned}
$$

Through Laplace transformation of the above two equations, the transfer function $H_{u}(s)=F_{c}(s) / F_{u}(s)$ between the control force $F_{u}(s)$ and contact force $F_{c}(s)$ can be formulated. As $K_{s}(t)$ is time-varying, its mean value $(4000 \mathrm{~N} / \mathrm{m})$ is adopted in this discussion. 


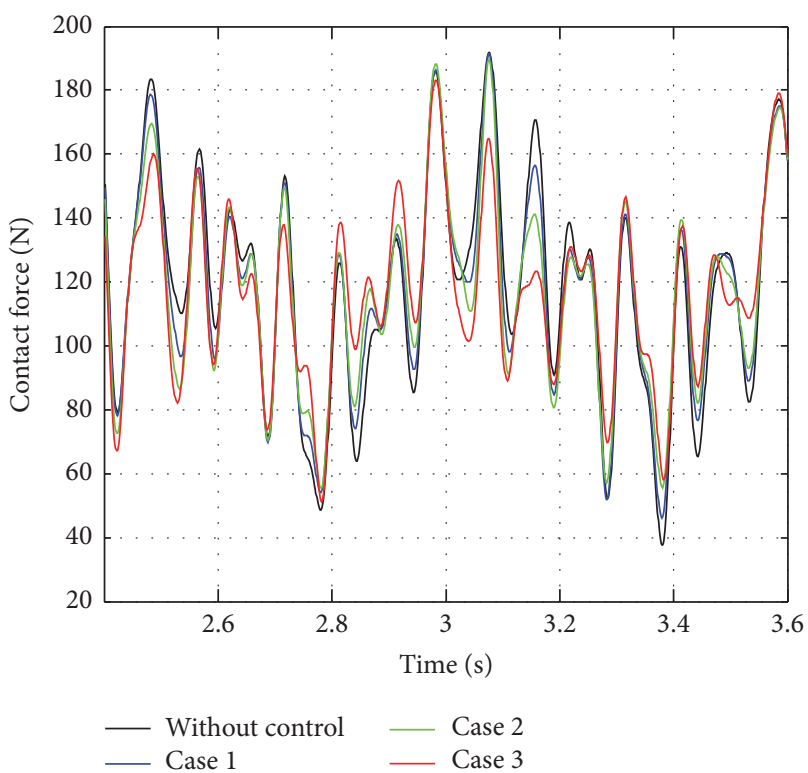

(a) Contact force

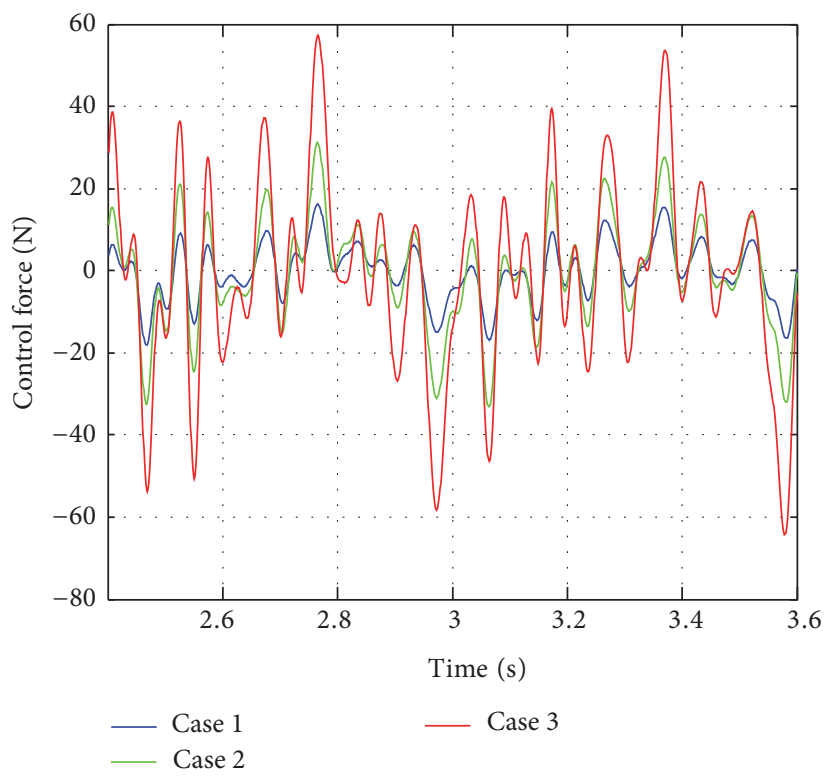

(b) Control force

FIGURE 13: Contact force and control force with proportional switching law.

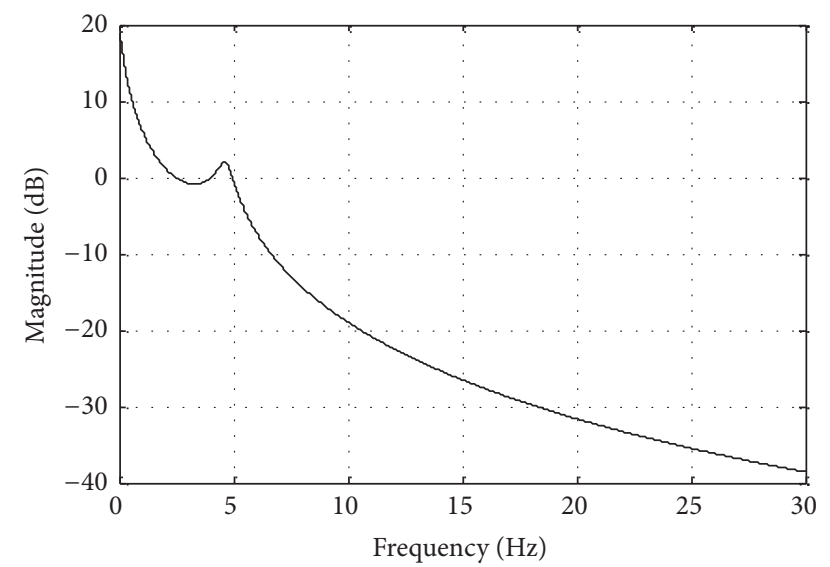

FIGURE 14: Frequency response between the control force $F_{u}(s)$ and contact force $F_{c}(s)$.

The frequency response between the control force $F_{u}(s)$ and contact force $F_{c}(s)$ is shown in Figure 14. It can be seen that the magnitude shows a sharp decrease with the increase of the frequency. On $\mathrm{dB}$ scale, when the magnitude is less than $0 \mathrm{~dB}$, the response will be smaller than the input. Through the Fast Fourier Transform of the control force in Figure 13(b), the amplitudes of control force at different frequencies are shown in Figure 15. It can be seen that, apart from the first peak appearing at $1.68 \mathrm{~Hz}$ (whose amplitudes are only $12.3 \mathrm{~N}$, $8.2 \mathrm{~N}$, and $5 \mathrm{~N}$, resp., in those three cases), almost all the dominant frequencies of control force are over $5 \mathrm{~Hz}$, whose effect on contact force is definitely reduced by the pantograph system. This analysis is consistent to our previous knowledge of the pantograph, which has a low natural frequency and serves as a low-pass filter for the disturbance transmitted from the bottom of pantograph to its head.

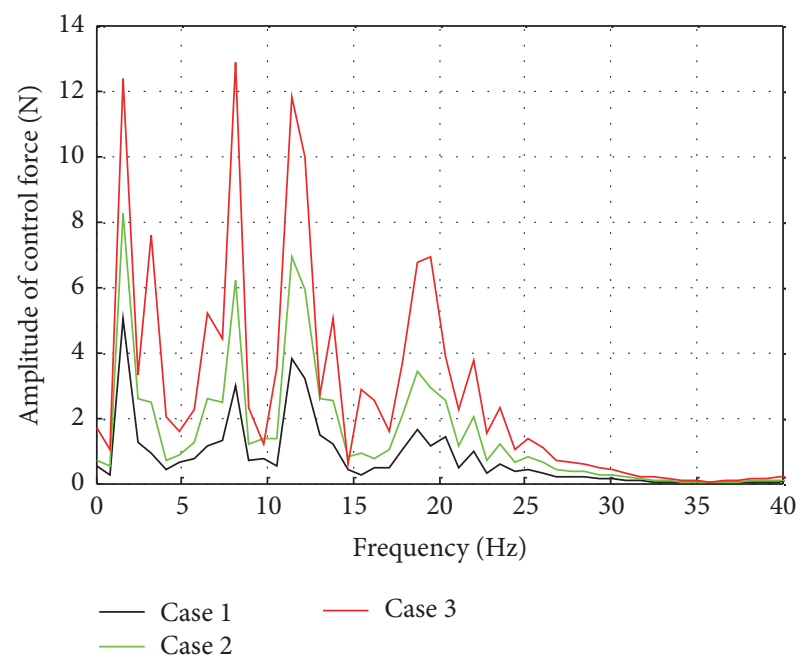

FIGURE 15: Amplitude of control force at different frequencies.

4.2. Evaluation of Control Performance with Wind Load. When the external disturbance is included, the fluctuation in contact force would increase significantly, and contact loss may occur. So the control performance of the proposed controller is evaluated under stochastic wind field. The wind speeds are chosen as $20 \mathrm{~m} / \mathrm{s}$ and $30 \mathrm{~m} / \mathrm{s}$, respectively. The angles of attack are chosen from $-60^{\circ}$ to $0^{\circ}$. The results of standard deviation of contact force with the wind speed of $20 \mathrm{~m} / \mathrm{s}$ and $30 \mathrm{~m} / \mathrm{s}$ are shown in Figures 16(a) and 16(b), respectively. The more closely the wind flows to the vertical direction, the larger the standard deviation of contact force becomes, and the more significant the control performance becomes. Case 3 shows the best control performance in decreasing the fluctuation in contact force under different 


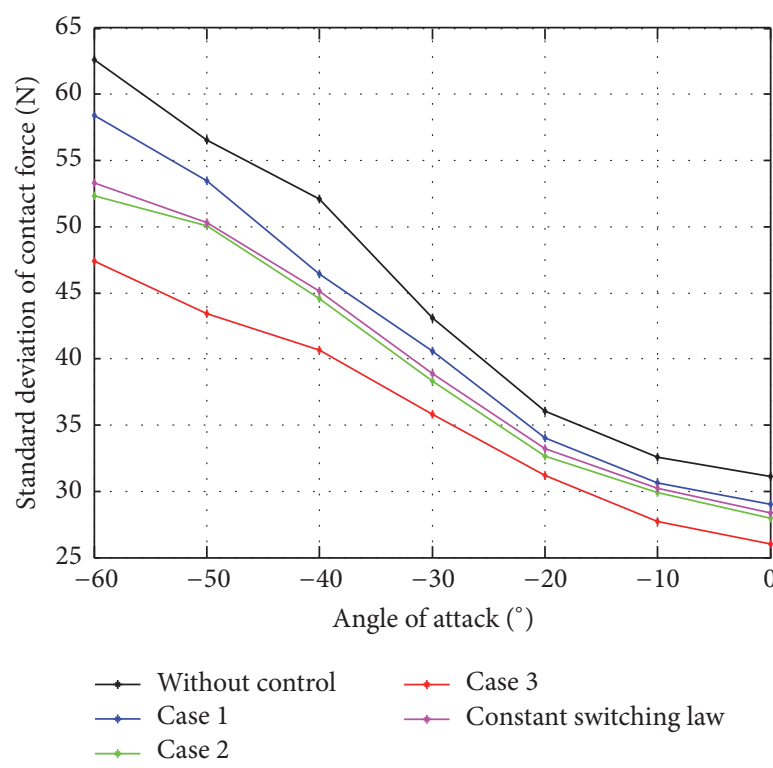

(a) Wind speed $20 \mathrm{~m} / \mathrm{s}$

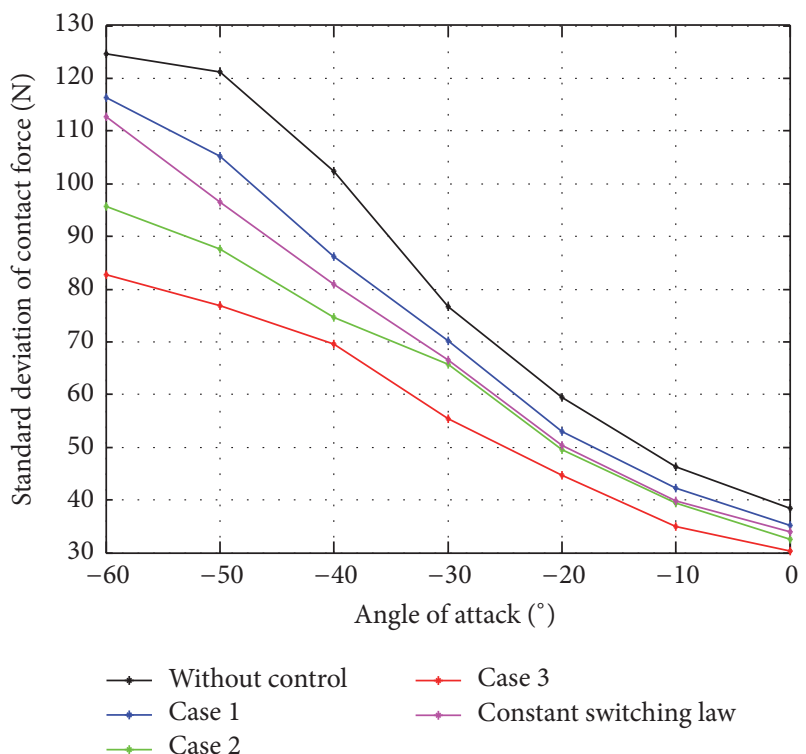

(b) Wind speed $30 \mathrm{~m} / \mathrm{s}$

FIGURE 16: Results of standard deviation of contact force with different wind speeds and angles of attack.

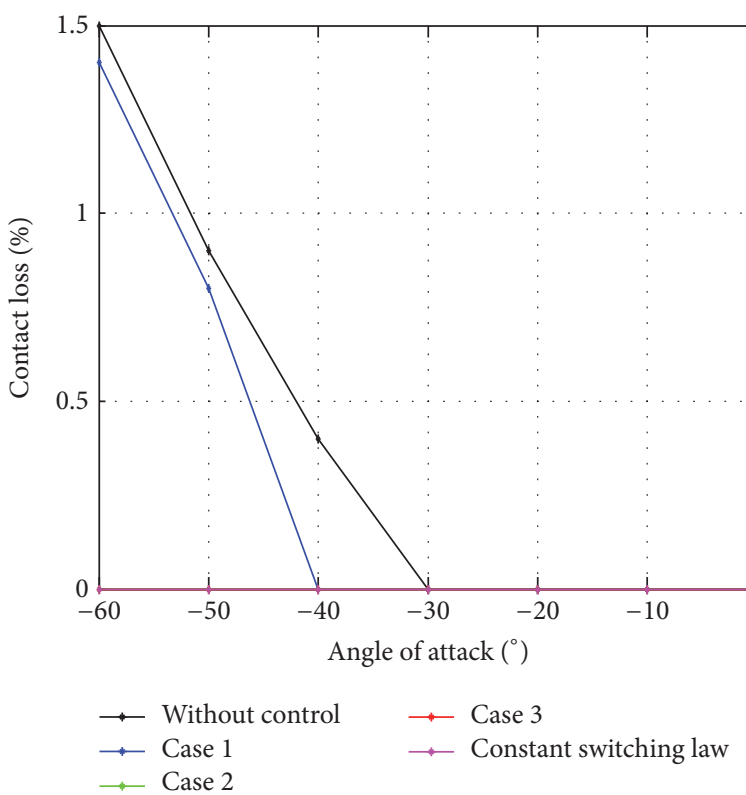

(a) Wind speed $20 \mathrm{~m} / \mathrm{s}$

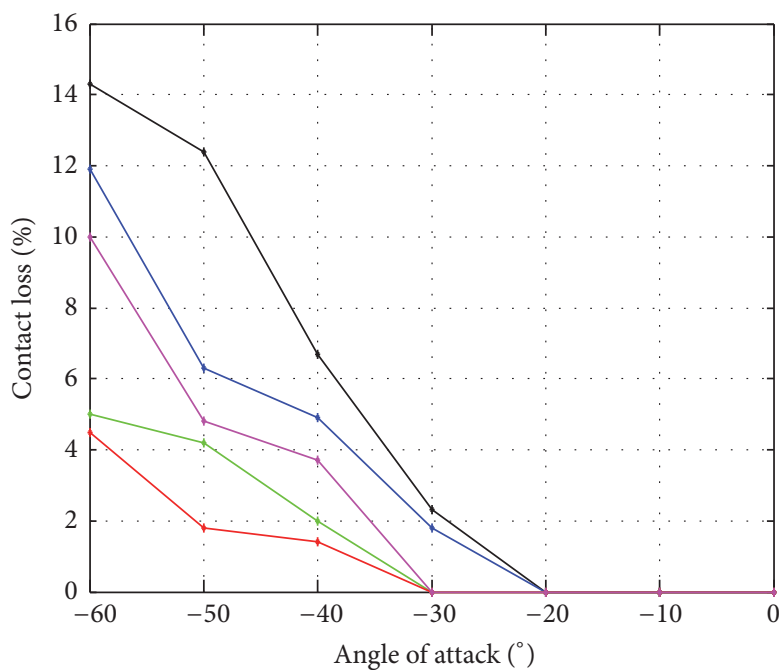

$\rightarrow$ Without control $\rightarrow$ Case 3
$\rightarrow$ Case 1
$\rightarrow$ Case 2

(b) Wind speed $30 \mathrm{~m} / \mathrm{s}$

Figure 17: Results of percentage of contact loss with different wind speeds and angles of attack.

wind speeds and angles of attack. For the comparison with the proportional switching law, the constant switching controller with $u=40 \mathrm{~N}$ is adopted in the simulation, which shows the best control performance among different constant switching laws in the above analysis. It can be found that the constant switching controller with $u=40 \mathrm{~N}$ shows a better control performance than case 1 but worse control performance than case 2 with each angle of attack.

The strong wind load may cause the separation between the pantograph and catenary. The results of contact loss percentage with different angles of attack under the wind speeds of $20 \mathrm{~m} / \mathrm{s}$ and $30 \mathrm{~m} / \mathrm{s}$ are shown in Figures 17 (a) and 17(b), respectively. From Figure 17(a), it can be seen that the contact loss can be totally eliminated by the proportional switching controller of case 2 and case 3 , as well as the constant switching controller with $u=40 \mathrm{~N}$ under each angle of attack. When the wind speed reaches $30 \mathrm{~m} / \mathrm{s}$, the maximum percentage of contact loss can increase to $14.2 \%$. It is obvious that, due to the effect of the controller, the percentage of contact loss experiences a significant decline and drops to $0 \%$ 
TABLE 3: 10 sets of control gains.

\begin{tabular}{lcccccccccc}
\hline Case & 1 & 2 & 3 & 4 & 5 & 6 & 7 & 8 & 9 & 10 \\
\hline$\alpha$ & 0.1 & 0.2 & 0.3 & 0.4 & 0.5 & 0.6 & 0.7 & 0.8 & 0.9 & 1 \\
$\beta$ & $5 \times 10^{-5}$ & $1 \times 10^{-4}$ & $1.5 \times 10^{-4}$ & $2 \times 10^{-4}$ & $2.5 \times 10^{-4}$ & $3 \times 10^{-4}$ & $3.5 \times 10^{-4}$ & $4 \times 10^{-4}$ & $4.5 \times 10^{-4}$ & $5 \times 10^{-4}$ \\
\hline
\end{tabular}

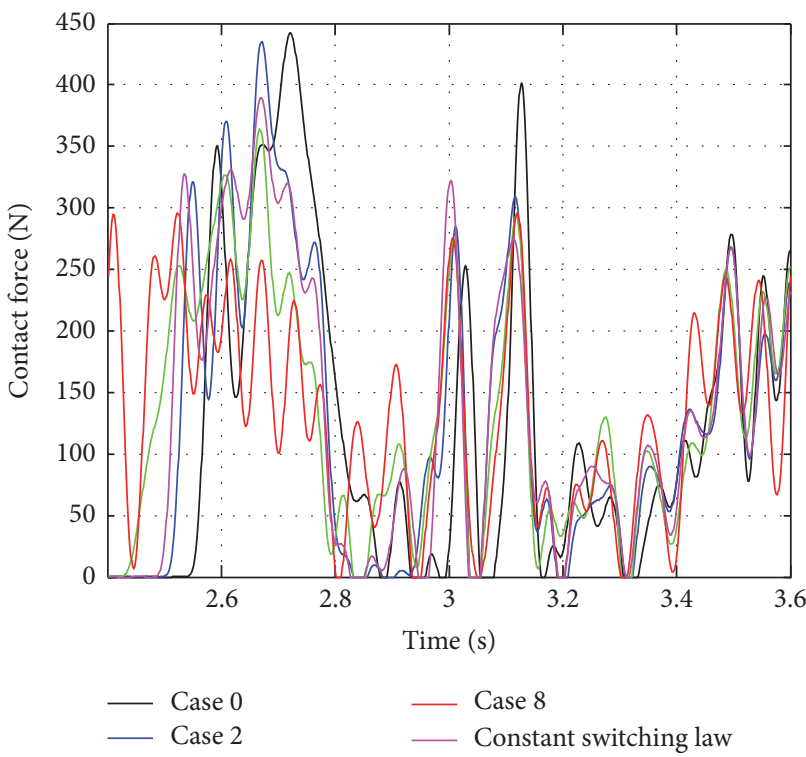

(a) Contact force

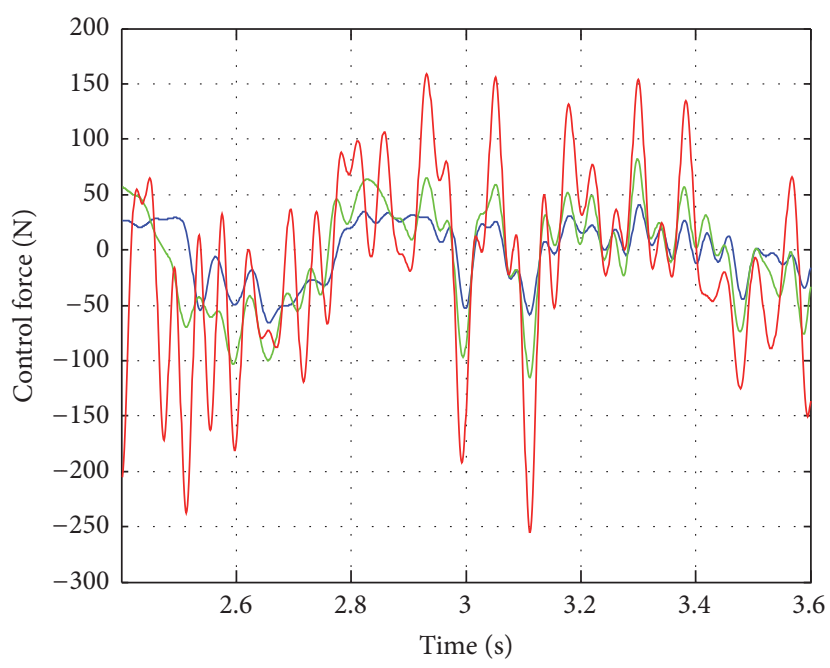

Case 2
Case 4
Case 8

FIGURE 18: Results of contact force and control force with case 0 , case 2, case 4, and case 8.

even when the angle of attack increases by more than $-20^{\circ}$. The proportional switching controller of case 3 has the best control effect to reduce the contact loss compared with other controllers.

In the following analyses, the wind angle of $-60^{\circ}$ and wind velocity of $30 \mathrm{~m} / \mathrm{s}$ are adopted to study the effect of the controller on the contact force in more detail with more sets of control gains. 10 sets of control gains are adopted for the analysis in Table 3.

The results of the contact force in case 0 , case 2 , case 4 , and case 8 are presented in Figure 18(a). Different from the nonsignificant effect of the controller in the above investigation without wind load (in Section 4.1), the control performance can be very clearly observed under the strong wind load, displaying a significant reduction of the contact loss.

The results of the corresponding control force of the proportional switching controllers are plotted in Figure 18(b). It can be found that a better control performance needs a larger consumption of the energy. The largest control force appears with case 8 . When the wind speed reaches $30 \mathrm{~m} / \mathrm{s}$, the maximum control force reaches more than $250 \mathrm{~N}$, which is more than twice as large as the static uplift force of the pantograph and may be difficult to implement in reality. So a proper set of control gains should be chosen according to the practical environmental situation and the limitation of the actuator. On the other hand, it can be observed that the controller introduces some negative effect on the contact force which was not present originally. This is because the catenary system exhibits strong nonlinearity, which is very difficult to control. As shown in Figure 18(a), during the time duration of interest, the performance of the controller is not very good at a few isolated time instants. However, on the whole, the total fluctuation and contact loss are decreased considerably.

In order to make sense of the effect of the controller on contact force in detail, several indexes are introduced to evaluate the control performance, which include the standard deviation, the percentage of contact loss, the number of occurrences of contact loss, the mean value of contact loss, the maximum interval of separation, and the maximum value of control force. The results of standard deviation of contact force and the maximum interval of separation are shown in Figures 19(a) and 19(b), respectively. It can be seen that the increase of the control gains can decrease the standard deviation of contact force, which means a lower fluctuation in contact force. Simultaneously, the maximum interval of separation is effectively decreased by the controller with larger control gains, which can reduce the risk of interruption of the electric transmission.

The results of mean value of contact force and the maximum control force are shown in Figures 20(a) and 20(b), respectively. It can be seen that the mean value of contact force is not largely affected by the controller, which cannot lead to a significant additional wear of the contact wire. The maximum control force experiences a sharp increase as the 


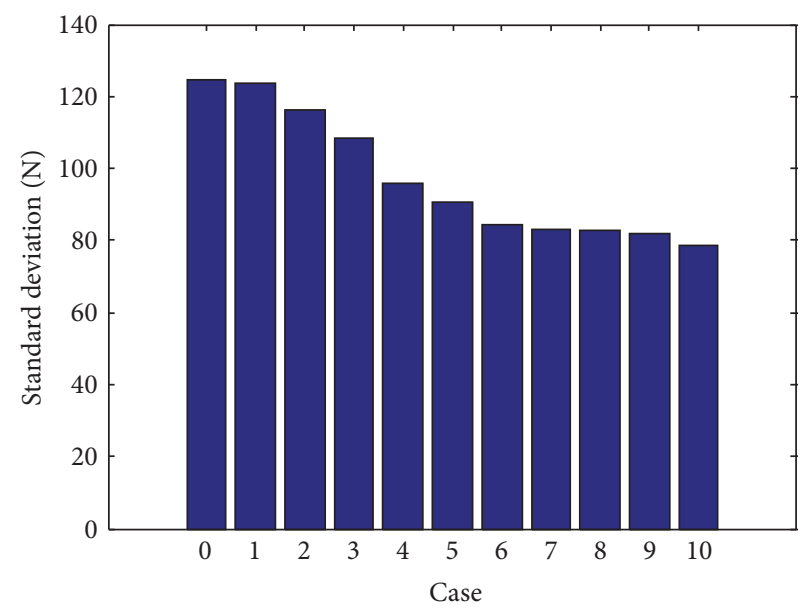

(a) Standard deviation

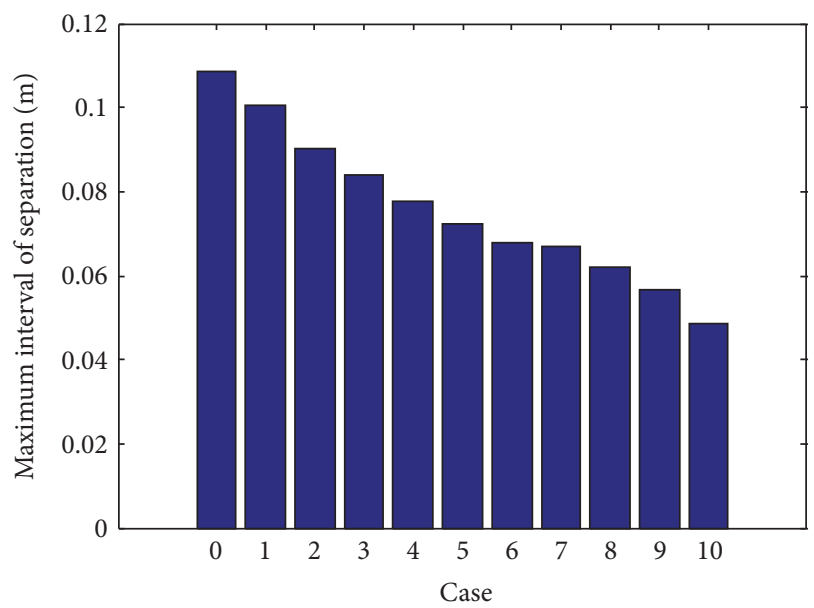

(b) Maximum interval of separation

FIGURE 19: The results of standard deviation of contact force and maximum interval of separation.

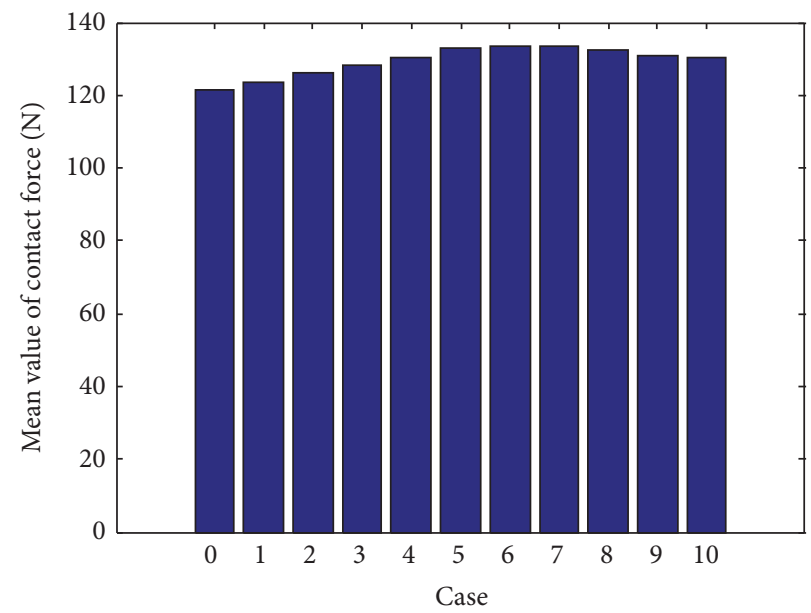

(a) Mean value of contact force

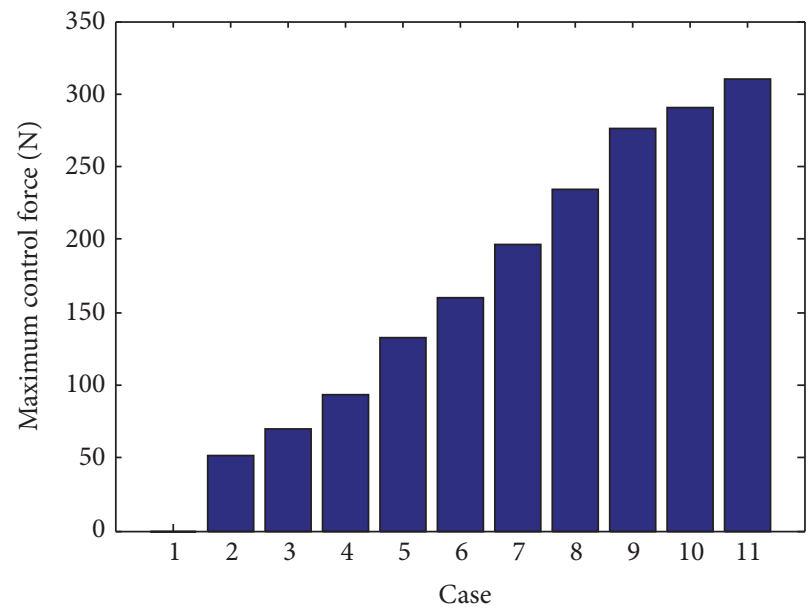

(b) Maximum control force

Figure 20: The results of mean value of contact force and maximum control force.

increase of the control gains (from case 0 to case 10). In combination to the analysis of Figure 19, it can be found that a better control performance requires a larger consumption of the control energy. It should be noted that when the control gains increase more than case 5 , the maximum control force begins to be more than the value of uplift force of the pantograph, which is quite difficult to be realized in reality.

The results of percentage of contact loss and the number of contact loss occurrences are shown in Figures 21(a) and 21(b), respectively. It can be seen that, generally, the contact loss and the number of its occurrences are decreased by the controller. However, the trends are not strictly consistent to the results in Figure 19. In particular the controllers with case 4 and case 6 have better performance in reducing the contact loss of the pantograph-catenary system compared to others.

4.3. Comparison with an Existing Controller. Reference [27] used a PID control strategy on EN 50318 reference model of pantograph-catenary system based on a minimum variance principle without any external disturbances and achieved a $10 \%$ reduction in the contact force variance. The controller in that work was comprised of a positive proportion gain and a positive integration gain. The maximum control force in that strategy was limited to no more than $100 \mathrm{~N}$. In order to evaluate the efficiency of the proposed control strategy in this paper, the same reference model in EN 50318 is adopted and the comparison of the control performance with [27] is conducted. In the simulation, the proportional switching law is utilized and the control gains are chosen as $\alpha=0.9$ and $\beta=-6 \times 10^{-4}$, which can guarantee that the range of control force is consistent with those in [27]. The results of the contact force are shown in Figure 22(a) and those of the control force are shown in Figure 19(b). A statistical analysis finds that the contact force variance decreases from $1314 \mathrm{~N}^{2}$ (without control) to $940 \mathrm{~N}^{2}$ (with control). The reduction of the contact force variance reaches more than $25 \%$, which is significantly better than the previous result. 


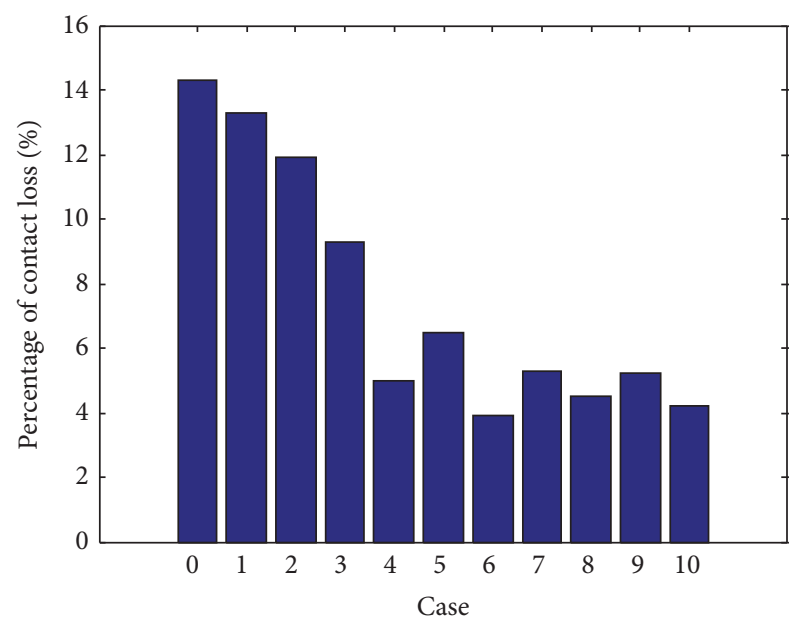

(a) Percentage of contact loss

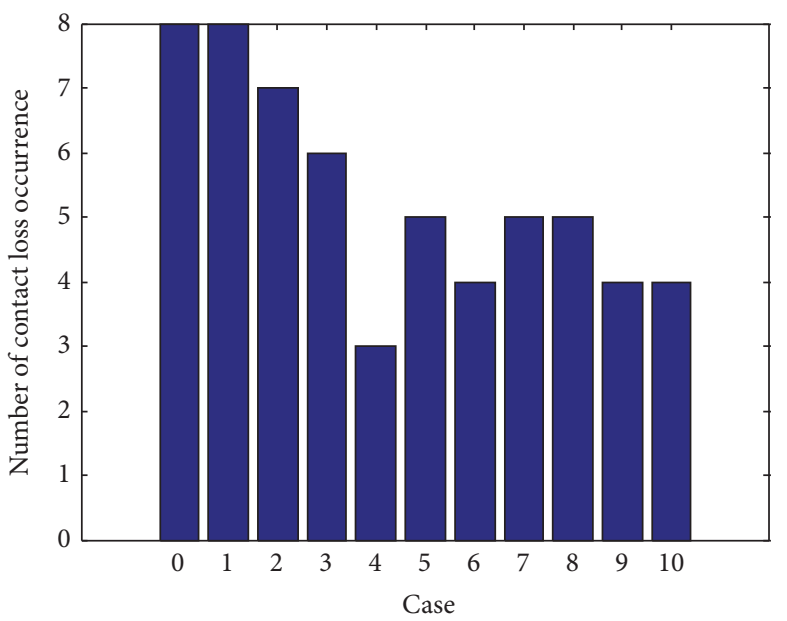

(b) Number of contact loss occurrences

FIgURE 21: The results of Percentage of contact loss and number of contact loss occurrences.

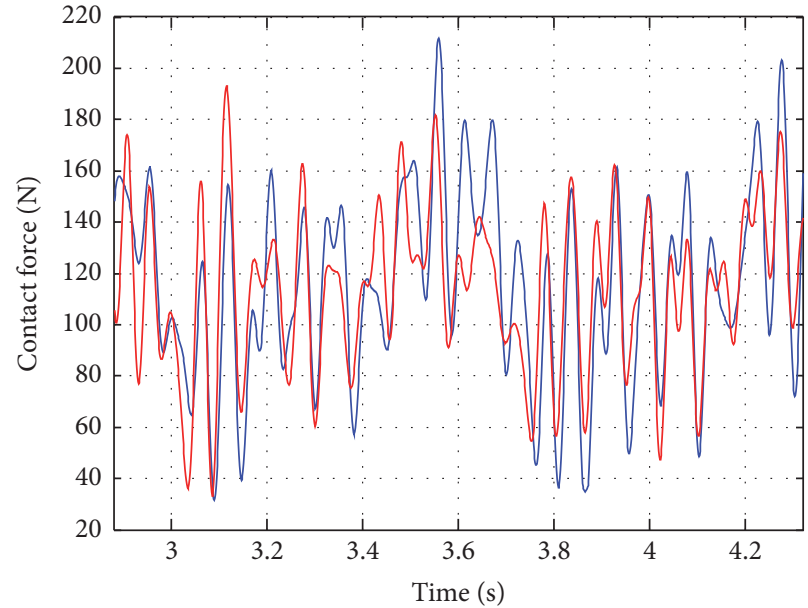

- Without control With control

(a) Contact force

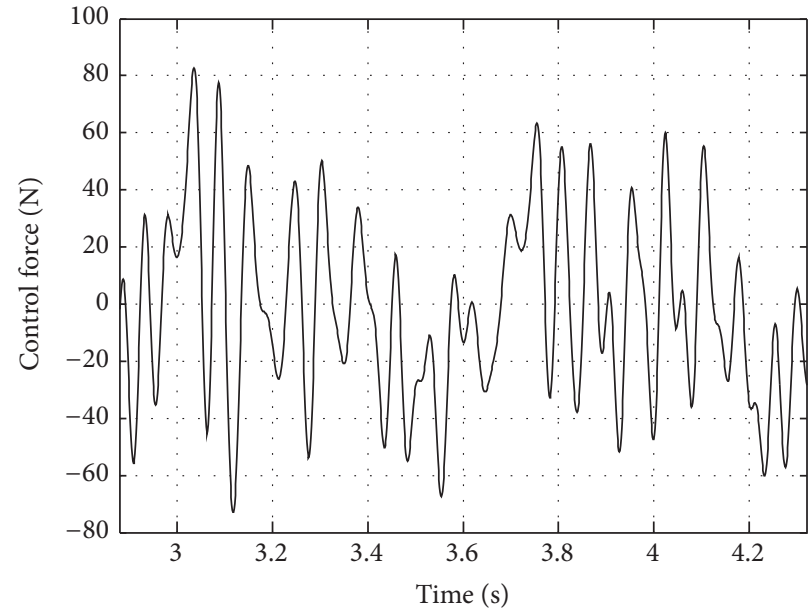

(b) Control force

FIGURE 22: Results of the contact force and control force with EN 50318 reference model.

\section{Conclusions and Future Works}

In this paper, a pantograph-catenary interaction model under a strong stochastic wind field is constructed based on a nonlinear finite element procedure. In order to decrease the fluctuation in contact force and reduce the loss of contact under a strong wind field, a sliding mode control strategy with a PD sliding surface is presented. The transfer function between the contact force and the pantograph head velocity (called mechanical impedance) is established. A proper sliding surface is defined to guarantee that the mechanical impedance of pantograph head decreases at the dominant frequencies of the contact force when the sliding surface approaches zero. Then the proportional switching controller with several sets of control gains and the constant switching controller are presented in the numerical simulations under the stochastic wind field with different wind speeds and angles of attack. The results indicate that the proposed control strategy has a good performance in decreasing the contact force fluctuation and the contact loss under strong wind field. The best results are obtained using the proportional switching law with a set of large control gains. However a better control performance needs a larger consumption of actuation energy. Through the comparison with the current literature, the proposed control strategy shows a better performance in decreasing the contact force variance $(25 \%)$ compared to previous method (10\%).

\section{Competing Interests}

The authors declare that they have no competing interests. 


\section{Acknowledgments}

This work was supported in part by the National Nature Science Foundation of China (U1434203, 51377136, and 51407147), Scientific Research and Development Program for Railway Ministry (2013J010-B), Sichuan Province Youth Science and Technology Innovation Team (2016TD0012), and Excellent Doctoral Thesis Cultivation Program of Southwest Jiaotong University.

\section{References}

[1] O. Lopez-Garcia, A. Carnicero, and V. Torres, "Computation of the initial equilibrium of railway overheads based on the catenary equation," Engineering Structures, vol. 28, no. 10, pp. 1387-1394, 2006.

[2] M. Tur, E. García, L. Baeza, and F. J. Fuenmayor, "A 3D absolute nodal coordinate finite element model to compute the initial configuration of a railway catenary," Engineering Structures, vol. 71, pp. 234-243, 2014.

[3] J. Ambrósio, J. Pombo, F. Rauter et al., "A memory based communication in the co-simulation of multibody and finite element codes for pantograph-catenary interaction simulation," in Multibody Dynamics, pp. 231-252, Springer, Amsterdam, The Netherlands, 2009.

[4] P. Nåvik, A. Rønnquist, and S. Stichel, "Identification of system damping in railway catenary wire systems from full-scale measurements," Engineering Structures, vol. 113, pp. 71-78, 2016.

[5] H. Wang, Z. Liu, Y. Song et al., "Detection of contact wire irregularities using a quadratic time-frequency representation of the pantograph-catenary contact force," IEEE Transactions on Instrumentation and Measurement, vol. 65, no. 6, pp. 1385-1397, 2016.

[6] J. H. Lee, T. W. Park, H. K. Oh, and Y. G. Kim, "Analysis of dynamic interaction between catenary and pantograph with experimental verification and performance evaluation in new high-speed line," Vehicle System Dynamics, vol. 53, no. 8, pp. 1117-1134, 2015.

[7] Y. Song, Z. Liu, H. Wang, X. Lu, and J. Zhang, "Nonlinear modelling of high-speed catenary based on analytical expressions of cable and truss elements," Vehicle System Dynamics, vol. 53, no. 10, pp. 1455-1479, 2015.

[8] A. Carnicero, J. R. Jimenez-Octavio, C. Sanchez-Rebollo, A. Ramos, and M. Such, "Influence of track irregularities in the catenary-pantograph dynamic interaction," Journal of Computational and Nonlinear Dynamics, vol. 7, no. 4, Article ID 041015, 2012.

[9] J. Pombo, J. Ambrosio, M. Pereira, F. Rauter, A. Collina, and A. Facchinetti, "Influence of the aerodynamic forces on the pantograph-catenary system for high-speed trains," Vehicle System Dynamics, vol. 47, no. 11, pp. 1327-1347, 2009.

[10] Y. Song, Z. Liu, H. Wang, X. Lu, and J. Zhang, "Nonlinear analysis of wind-induced vibration of high-speed railway catenary and its influence on pantograph-catenary interaction," Vehicle System Dynamics, vol. 54, no. 6, pp. 723-747, 2016.

[11] J.-H. Lee, Y.-G. Kim, J.-S. Paik, and T.-W. Park, "Performance evaluation and design optimization using differential evolutionary algorithm of the pantograph for the high-speed train," Journal of Mechanical Science and Technology, vol. 26, no. 10, pp. 3253-3260, 2012.

[12] J. Ambrósio, J. Pombo, and M. Pereira, "Optimization of highspeed railway pantographs for improving pantograph-catenary contact," Theoretical and Applied Mechanics Letters, vol. 3, no. 1, Article ID 013006, 2013.

[13] A. Rønnquist and P. Nåvik, "Dynamic assessment of existing soft catenary systems using modal analysis to explore higher train velocities: a case study of a Norwegian contact line system," Vehicle System Dynamics, vol. 53, no. 6, pp. 756-774, 2015.

[14] P. Nåvik, A. Rønnquist, and S. Stichel, “The use of dynamic response to evaluate and improve the optimization of existing soft railway catenary systems for higher speeds," Proceedings of the Institution of Mechanical Engineers, Part F: Journal of Rail and Rapid Transit, vol. 230, no. 4, pp. 1388-1396, 2015.

[15] Z. Liu, P. A. Jönsson, S. Stichel, and A. Ronnquist, "Implications of the operation of multiple pantographs on the soft catenary systems in Sweden," Proceedings of the Institution of Mechanical Engineers, Part F: Journal of Rail and Rapid Transit, vol. 230, no. 3, pp. 971-983, 2016.

[16] A. Facchinetti, L. Gasparetto, and S. Bruni, "Real-time catenary models for the hardware-in-the-loop simulation of the pantograph-catenary interaction," Vehicle System Dynamics, vol. 51, no. 4, pp. 499-516, 2013.

[17] H. Ouyang, "Moving-load dynamic problems: a tutorial (with a brief overview)," Mechanical Systems and Signal Processing, vol. 25, no. 6, pp. 2039-2060, 2011.

[18] Y. Pi and H. Ouyang, "Lyapunov-based boundary control of a multi-span beam subjected to moving masses," Journal of Vibration and Control, 2015.

[19] D. Stancioiu and H. Ouyang, "Optimal vibration control of beams subjected to a mass moving at constant speed," Journal of Vibration and Control, vol. 22, no. 14, pp. 3202-3217, 2016.

[20] Y.-C. Lin, C.-L. Lin, and C.-C. Yang, "Robust active vibration control for rail vehicle pantograph," IEEE Transactions on Vehicular Technology, vol. 56, no. 4, pp. 1994-2004, 2007.

[21] Y.-C. Lin, N.-C. Shieh, and V.-T. Liu, "Optimal control for rail vehicle pantograph systems with actuator delays," IET Control Theory \& Applications, vol. 9, no. 13, pp. 1917-1926, 2015.

[22] A. Rachid, "Pantograph catenary control and observation using the LMI approach," in Proceedings of the 50th IEEE Conference on Decision and Control and European Control Conference (CDC-ECC '11), pp. 2287-2292, IEEE, Orlando, Fla, USA, December 2011 .

[23] D. N. O'Connor, S. D. Eppinger, W. P. Seering, and D. N. Wormley, "Active control of a high-speed pantograph," Journal of Dynamic Systems, Measurement and Control, vol. 119, no. 1, pp. 1-4, 1997.

[24] A. Pisano and E. Usai, "Output-feedback regulation of the contact-force in high-speed train pantographs," Journal of Dynamic Systems, Measurement and Control, vol. 126, no. 1, pp. 82-87, 2004.

[25] J. Wang, "Active Control of Contact Force for a PantographCatenary System," Shock and Vibration, vol. 2016, Article ID 2735297, 7 pages, 2016.

[26] A. Pisano and E. Usai, "Contact force regulation in wireactuated pantographs via variable structure control and frequency-domain techniques," International Journal of Control, vol. 81, no. 11, pp. 1747-1762, 2008.

[27] C. Sanchez-Rebollo, J. R. Jimenez-Octavio, and A. Carnicero, "Active control strategy on a catenary-pantograph validated model," Vehicle System Dynamics, vol. 51, no. 4, pp. 554-569, 2013. 
[28] C. M. Pappalardo, M. D. Patel, B. Tinsley et al., "Contact force control in multibody pantograph/catenary systems," Proceedings of the Institution of Mechanical Engineers, Part K: Journal of Multi-Body Dynamics, vol. 230, no. 4, pp. 307-328, 2016.

[29] Y. Pi and H. Ouyang, "Vibration control of beams subjected to a moving mass using a successively combined control method," Applied Mathematical Modelling, vol. 40, no. 5-6, pp. 4002-4015, 2016.

[30] S. Bruni, J. Ambrosio, A. Carnicero et al., "The results of the pantograph-catenary interaction benchmark," Vehicle System Dynamics, vol. 53, no. 3, pp. 412-435, 2015.

[31] A. G. Davenport, "The application of statistical concepts to the wind loading of structures," Proceedings of the Institution of Civil Engineers, vol. 19, no. 4, pp. 449-472, 1961.

[32] H. A. Panofsky and R. A. McCormick, "The spectrum of vertical velocity near the surface," Quarterly Journal of the Royal Meteorological Society, vol. 86, no. 370, pp. 495-503, 1960.

[33] M. Aboshi and K. Manabe, "Analyses of contact force fluctuation between catenary and pantograph," Quarterly Report of RTRI, vol. 41, no. 4, pp. 182-187, 2000. 


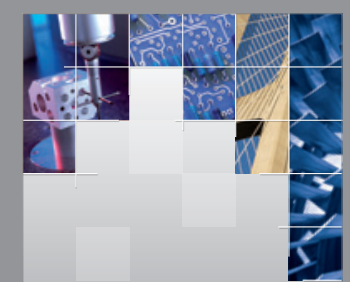

\section{Enfincering}
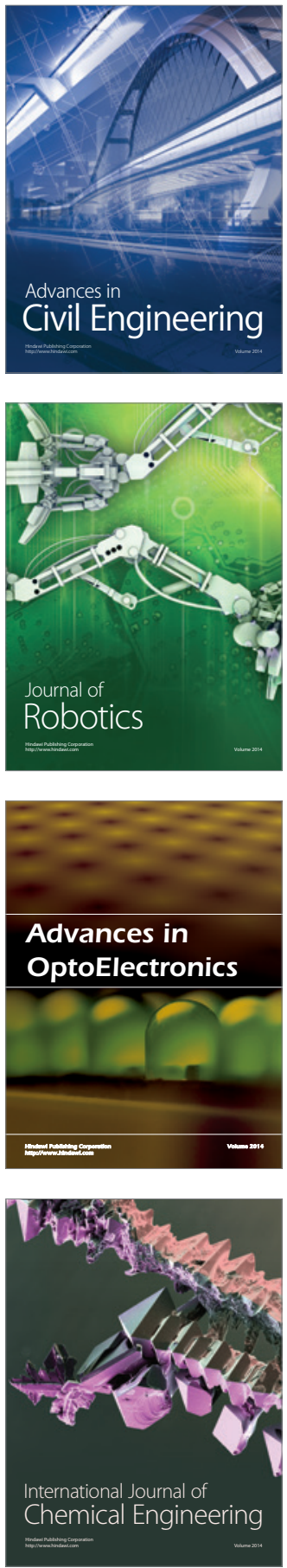

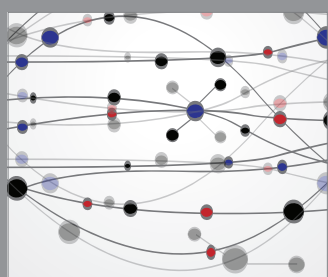

The Scientific World Journal

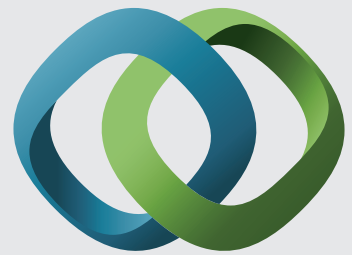

\section{Hindawi}

Submit your manuscripts at

https://www.hindawi.com
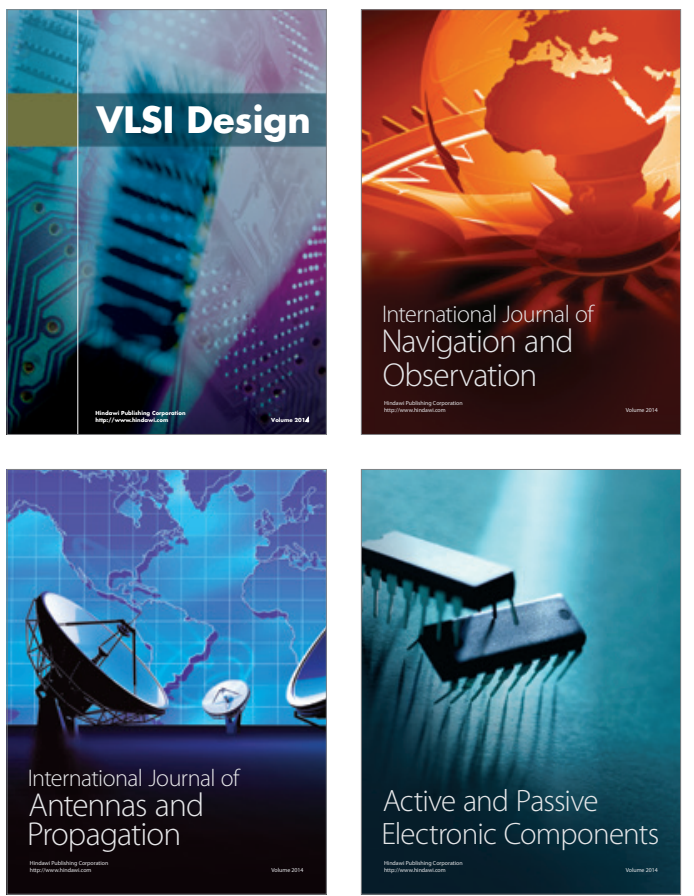
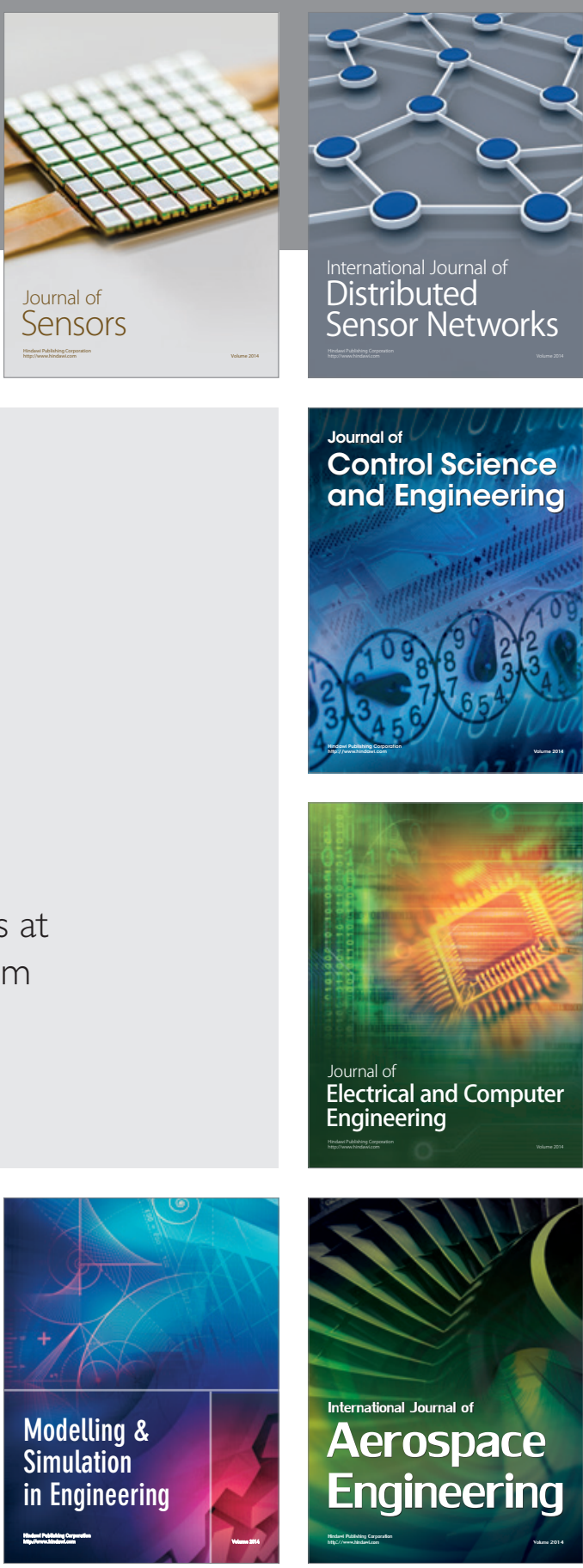

International Journal of

Distributed

Sensor Networks

$-$

Joumal of

Control Science

and Engineering
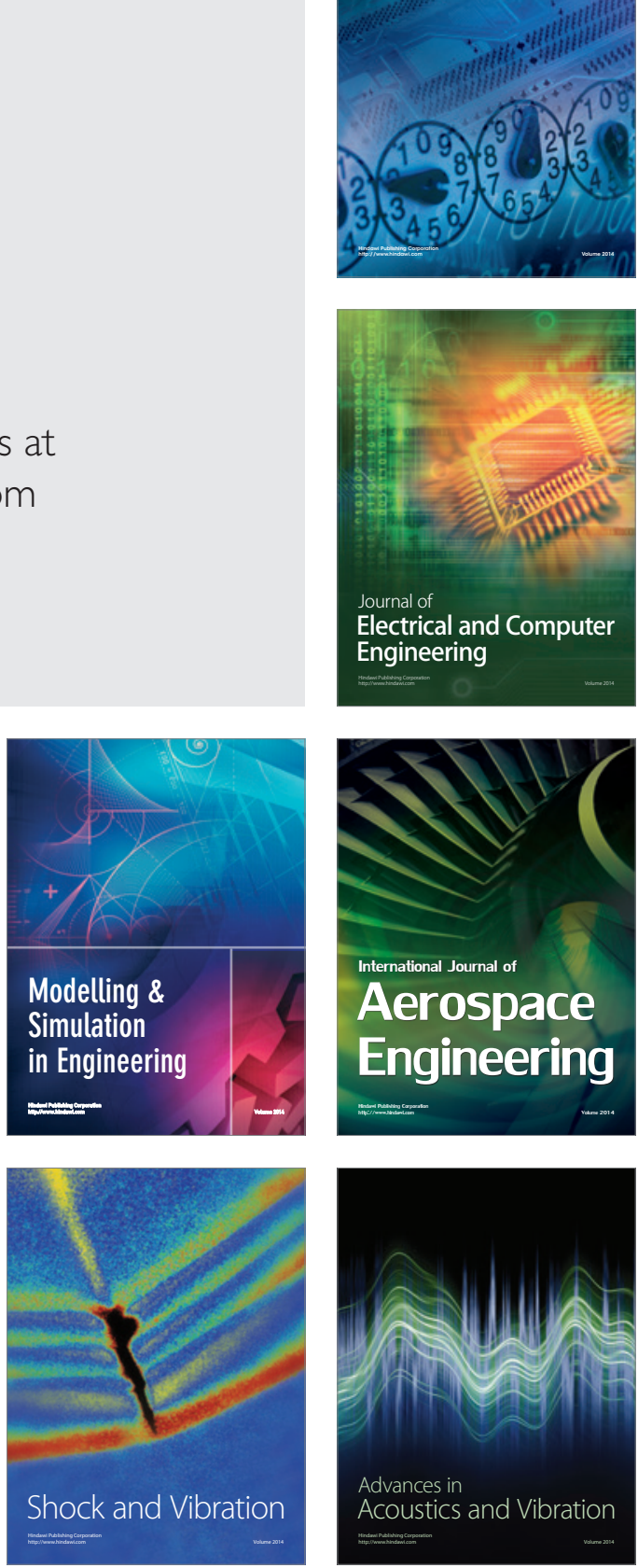